\title{
Assessment of elliptic flame front propagation characteristics of iso-octane, gasoline, M85 and E85 in an optical engine
} \author{
Roy James Crookes ${ }^{\mathrm{a}}$, Alvaro Diez ${ }^{\mathrm{d}}$, Dongsheng Wen ${ }^{\mathrm{a}, \mathrm{e}}$ \\ ${ }^{a}$ School of Engineering and Materials Science, Queen Mary University of London, London E1 4NS, UK \\ ${ }^{\mathrm{b}}$ Parks College of Engineering, Aviation and Technology, Saint Louis University, St. Louis, MO 63103, USA \\ ' iEng Solutions Ltd., 2 Woodberry Grove, London N12 ODR, UK \\ ${ }^{\mathrm{d}}$ Izmir Institute of Technology, Gulbahce Campus, Izmir 35430, Turkey \\ e School of Process Environmental and Materials Engineering, University of Leeds, Leeds LS2 9JT, UK
}

Balazs Ihracska ${ }^{a}$, Theodosios Korakianitis ${ }^{\mathrm{b}, *, 1}$, Paula Ruiz ${ }^{\mathrm{c}}$, David Robert Emberson ${ }^{\mathrm{a}}$,

\section{A R T I C L E I N F O}

\section{Article history:}

Received 6 December 2012

Received in revised form 19 July 2013

Accepted 24 July 2013

Available online 12 August 2013

\section{Keywords:}

Flame speed

Spherical

Optical engine

Ethanol

Methanol

Gasoline

\begin{abstract}
A B S T R A C T
Premixed fuel-air flame propagation is investigated in a single-cylinder, spark-ignited, four-stroke optical test engine using high-speed imaging. Circles and ellipses are fitted onto image projections of visible light emitted by the flames. The images are subsequently analysed to statistically evaluate: flame area; flame speed; centroid; perimeter; and various flame-shape descriptors. Results are presented for gasoline, isooctane, E85 and M85. The experiments were conducted at stoichiometric conditions for each fuel, at two engine speeds of $1200 \mathrm{rpm}$ (rpm) and $1500 \mathrm{rpm}$, which are at 40\% and 50\% of rated engine speed. Furthermore, different fuel and speed sets were investigated under two compression ratios (CR: 5.00 and 8.14). Statistical tools were used to analyse the large number of data obtained, and it was found that flame speed distribution showed agreement with the normal distribution. Comparison of results assuming spherical and non-isotropic propagation of flames indicate non-isotropic flame propagation should be considered for the description of in-cylinder processes with higher accuracy. The high temporal resolution of the sequence of images allowed observation of the spark-ignition delay process. The results indicate that gasoline and isooctane have somewhat similar flame propagation behaviour. Additional differences between these fuels and E85 and M85 were also recorded and identified.
\end{abstract}

(C) 2013 The Combustion Institute. Published by Elsevier Inc. All rights reserved.

\section{Introduction}

The current issues with our hydrocarbon based economy and its effects on climate change and human life are well documented (for instance [1]). These environmental and socio-political issues are among the most motivating research drivers, providing impetus for research in renewable energy and design-to-specification fuels [2-5]. Nevertheless, developed as well as developing countries still rely to a great extent on conventional fuels powering conventional engines. There is still a lot of room for considerable improvement in understanding the chemical reaction and flame-propagation processes, and reducing the emissions of these engine-fuel combinations. One of the most important ways to analyse combustion processes in engines is to employ 3D-CFD codes, with incorporation of various well refined fuel oxidation and flame propagation mechanisms [6,7]. The models and codes need validation with experimental work accurately describing the exact nature of these in-cylinder processes.

\footnotetext{
* Corresponding author.

E-mail address: korakianitis@alum.mit.edu (T. Korakianitis).

1 a.k.a. Theodosios Alexander, publishes as Theodosios Korakianitis.
}

\subsection{Flame structure and propagation}

Although, flame is defined as the luminous part of the burning gases caused by highly exothermic, rapid oxidation [8]. For simplicity in this study, the earliest and relatively short plasma state of the glowing charge was also considered as a flame. For both moving and standing flames, the flame front is the indicator of where gases heat up and start emitting light $[9,10]$. This front is considered to consist of two regions: preheat and reaction zones. For instance, Fig. 1 illustrates the top view of the reaction and preheat zones in the chamber of the optical-access engine used in this paper.

The combustion process in SI engines can be divided into four main stages: spark and flame initiation; initial flame kernel development; turbulent flame propagation; and flame termination [11]. The first two stages are of high importance in terms of in-cylinder pressure development [12-16]. These four stages are influenced by: spark energy and duration [17]; spark plug design and orientation [18]; in-cylinder flow field [19]; cyclic cylinder charging [20]; in-cylinder composition [21]; and other related factors. A detailed literature survey on the effects of these parameters on the four stages of combustion appeared in [12]. 


\begin{tabular}{|c|c|c|c|}
\hline \multicolumn{4}{|c|}{ Nomenclature } \\
\hline & & $\sum$ & summation operator \\
\hline \multicolumn{4}{|l|}{ Latin } \\
\hline$A$ & area & \multicolumn{2}{|c|}{ Subscripts } \\
\hline$B$ & arbitary region & 0 & spark origin \\
\hline$c_{V}$ & isochoric specific heat capacity & 1,2 & integer \\
\hline d & infinitesimal difference operator & $b$ & fraction burned \\
\hline$d a$ & semi axial length & $i$ & integer \\
\hline$D_{F}$ & Feret's diameter & maj & major \\
\hline$f$ & arbitary function & $\min$ & minor \\
\hline$h$ & heating value & $p, w$ & integer \\
\hline LHV & lower heating value & $x, y, z$ & Cartesian coordinates, axes \\
\hline$m$ & mass & & \\
\hline$M$ & moment of a two dimensional region & \multicolumn{2}{|c|}{ Acronyms and abbreviations } \\
\hline 0 & parameter & BTDC & before top dead centre \\
\hline$p$ & pressure & $\mathrm{CA}$ & cranck angle \\
\hline$Q_{h t}$ & heat transfer to walls & CMOS & complementary metal-oxide semiconductor \\
\hline$r$ & radius & CFD & computational fluid dynamics \\
\hline RNS & roundness & $\mathrm{CH}$ & clearance height \\
\hline $\bar{S}$ & average flame speed & $\mathrm{COV}$ & coefficient of variance \\
\hline$S A$ & semi axes of an ellipse & $\mathrm{CR}$ & compression ratio \\
\hline Sf & shape factor & $\mathrm{D}$ & dimension \\
\hline$S_{n}$ & flame speed & EoI & end of imaging period \\
\hline$T$ & temperature & $\mathrm{EQR}$ & equivalent radius \\
\hline$t$ & time & EVC & exhaust valve closes \\
\hline$U$ & central moment & EVO & exhaust valve opens \\
\hline$u_{n}$ & turbulent burning velocity & $\mathrm{HC}$ & hydrocarbon \\
\hline$V$ & volume & IMEP & indicated mean effective pressure \\
\hline$v_{g}$ & gas expansion velocity & IVC & intake valve closes \\
\hline $\bar{x}$ & centroid & IVO & intake valve opens \\
\hline \multirow[t]{2}{*}{$\bar{y}$} & centroid & $\mathrm{rpm}$ & revolutions per minute \\
\hline & & RSE & relative standard error \\
\hline Greek & & SAFS & spherical assumption flame speed \\
\hline$\Delta$ & finite difference operator & TAI & time after ignition \\
\hline$\epsilon$ & axis orientation angle & TDC & top dead centre \\
\hline$\eta_{\text {Vol }}$ & volumetric Efficiency & Tol & time of ignition \\
\hline$\rho$ & density & & \\
\hline
\end{tabular}

The flame speed $S_{n}$ (which can be measured from images of the spatial-temporal development of the flame) is given by $[9,22]$ :

$S_{n}=v_{g}+u_{n}$

where $v_{g}$ is the gas expansion velocity immediately adjacent to the flame front and $u_{n}$ is the stretched laminar burning velocity of combusting air fuel mixture [23]. The turbulent burning velocity equals the laminar velocity with the added effect of the flow field, geometry; wrinkling of the flame front; pressure effects on flame thickness; history of the flame [24]. The effect of the turbulent flow field is crucial for the first and second stage of combustion. It has been shown that the smallest flame kernels are distorted shortly after ignition [25]. The laminar velocity is an intrinsic property of a combustible fuel, air and burned gas mixture. That is defined as the velocity, relative to and normal to the flame front, with which unburned gas moves into the front and is transformed to products [26].

Turbulent burning velocity plays a prime role and directly effects the in-cylinder pressure development, i.e., engine performance. Turbulent burning velocity and laminar burning velocity are important physical properties of fuel air mixtures. It is essential that both of these velocities are derived experimentally from flame speed and in-cylinder pressure measurements [9,14,11,22]. The work produced by an engine is related to the flame speed as can be inferred from the following. The burned mass of charge is given by
$m_{b}(t)=\left(\bar{S}_{x} \bar{S}_{y} \bar{S}_{z}\right)(t) \rho_{b}(t) S f(t)$,

where $\bar{S}_{x}, \bar{S}_{y}, \bar{S}_{z}$ are the average flame speeds in the $x, y, z$ directions. These can be determined by dividing the flame radius along an axis by the elapsed time from ignition. $S f$ is a shape specific function. The burning of fuel releases energy to the working fluid in the cylinder, given by $[26,4]$ :

$m_{b} L H V-\left(m c_{V} \mathrm{~d} T\right)-\Sigma h_{i} d m_{i}-\mathrm{d} Q_{h t}=p \mathrm{~d} V$

The rate of burning of the air-fuel mixture affects the chemical energy change of the fluid, and this directly affects the indicated work and power output. In Eq. (3) the work done on the piston $p \mathrm{~d} V$ equals the energy released from the burning fuel $m_{b} L H V$, minus the energy required to heat up the charge $m c_{V} \mathrm{~d} T$, minus the heat transfer to walls $d Q_{h t}$, and adjusted by the masses leaving or entering the chamber $\Sigma h_{i} \mathrm{~d} m_{i}$. Note: term $\Sigma h_{i} \mathrm{~d} m_{i}$ can be positive (during fuel injection) or negative (flow to crevice volumes or blow by). Therefore engine performance is highly dependent on flame propagation characteristics within the cylinder.

\subsection{Visualisation of initial flame kernel growth in SI engines}

In previous engine research images of flames in cylinders showed a significant enflamed volume, but the pressure measurements were not accurate or sensitive enough to indicate the evolving flame kernels $[21,15]$. Therefore, optical investigation of 


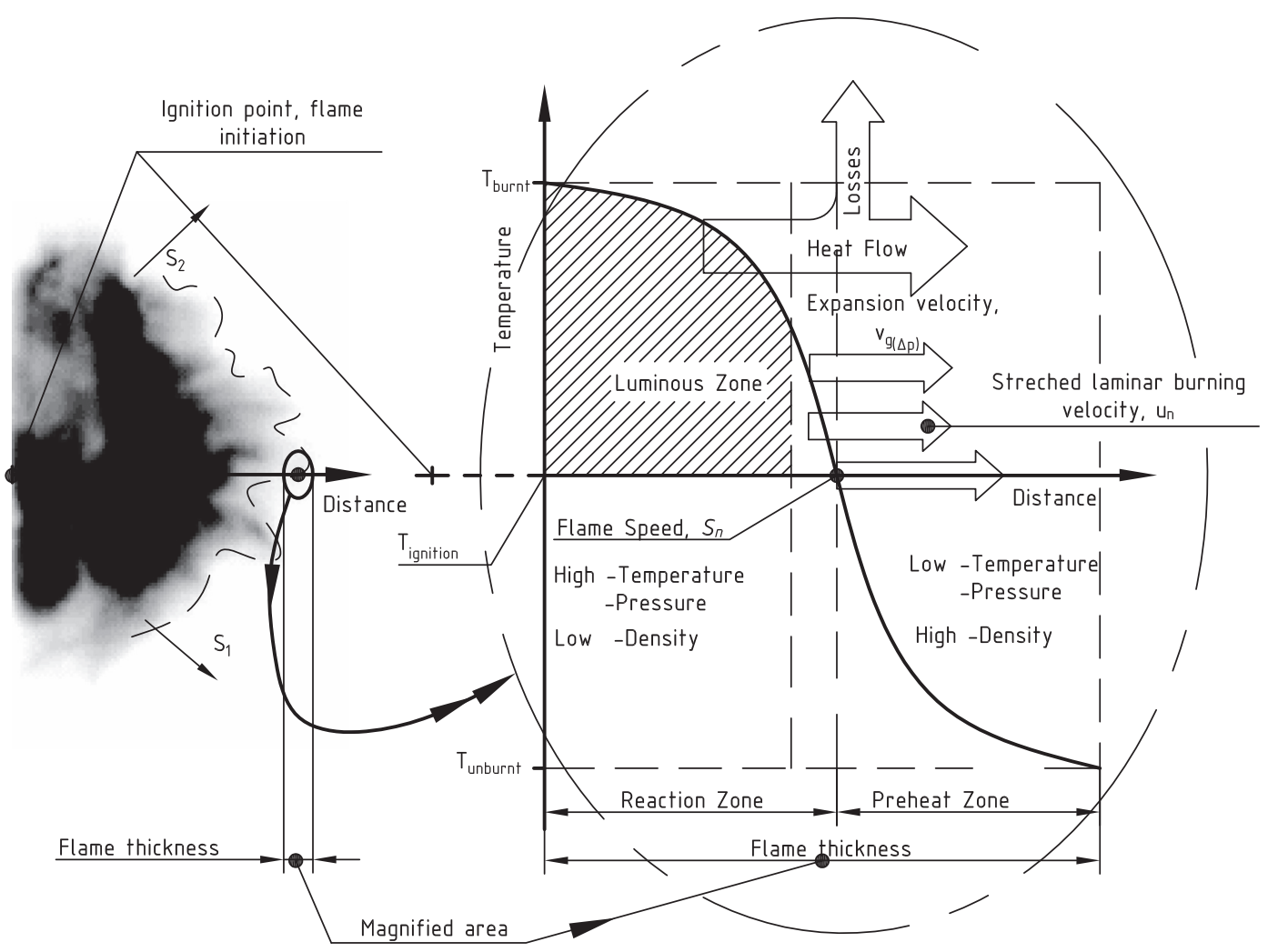

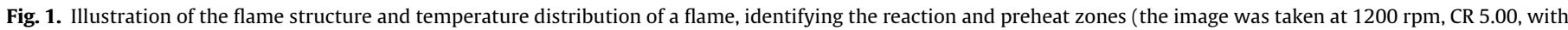
iso-octane).

combustion is preferred to pressure tracing at the early combustion stages. The practical realisation of visual access to a combustion chamber of a working piston engine is not easy, with any of the visible, ultra violet spectra or laser radiation approaches [4346]. The fluctuating pressure at high temperature, the limited strength of transparent materials and the geometrical constrains kept investigators from studying optical engines at real working conditions. In most cases the engine speed and $\mathrm{CR}$ were kept low in order to observe the propagating flames. In previous investigations the effect of changing engine speeds and equivalence ratios were studied. However, because of the tight cylinder geometries, there has been no optical data recorded in the same engine at different compression ratios. Another major difficulty is the time scale of rapid oxidation. The average of temporal resolution that can be found in the literature is about $0.2-0.4 \mathrm{~ms}$. Only one paper included data at higher temporal resolution, which could potentially provide insight to the earliest and faintest flames [32]. It has also been reported that fouling of the optical ports limits the length of operation time [18]. The experimental conditions and a general summary of the most relevant work on flame speed measurements and other investigations in optical engines can be found in Table 1. A comprehensive review of experimental investigation techniques in reciprocating-piston engines is in [47].

It has been shown that the shape of the evolving flame kernel has a major effect on the in-cylinder combustion processes [14]. Generally, previous studies have assumed that the propagation of the spark-initiated oxidation is isotropic, i.e. spherical flame propagation $[15,16,18,21,25,28,29,39,38,30-36]$. Only a few studies mentioned different flame-front geometries [14,15,30,39] and looked into implications arising from the assumption that the flame front surface had a spherical geometry. However, these shapes were not described mathematically and detailed analyses were not carried out.
Even though the in-cylinder flame front is a three-dimensional flame, in most studies flame-speed measurements are measured from two-dimensional projections of the images. Applying the isotropic propagation assumption, the two-dimensional projected contours of spherical flames can be digitized and their various geometrical properties determined. Actual flame speeds and flame shapes were measured in a small number of studies, where the flame radii were calculated using the "equivalent radius" (EQR) method $[39,25,15,38,16,32,33,40,41]$, which determines the radius from the measured area:

$r=\sqrt{\frac{A}{\pi}}$

where $r$ is the flame radius and $A$ is the area of the projected region. There has been no attempt to refine this assumption.

Many of the early investigators (that established the fundamentals of optical engine work) due to limitations of available tools used hand tracing methods to delineate the boundaries and/or had low number of samples (3-6 measurements averaged) [19]. Later papers do have a larger number of measurements, but statistical distribution of their findings was not documented [37]. Cyclic variability in engines is a widely studied phenomenon $[48,27,18,12]$ : the nature of the processes prior to ignition, the ignition itself and combustion instabilities cause fairly high standard deviation of in-cylinder measurements. Therefore statistical tools and high numbers of samples are needed in order to keep errors in the results low.

In previous studies with optical-access engines the main choice of fuels were pure hydrocarbons (HC), such as propane and isooctane. Less attention was paid to practical fuels such as gasoline and alcohol blends (Table 1). It is a usual practice to use isooctane as a surrogate of gasoline in engine related research purposes as these 
Table 1

Table of prior related publications.

\begin{tabular}{|c|c|c|c|c|c|c|c|c|}
\hline \multicolumn{3}{|l|}{ Research } & \multicolumn{3}{|l|}{ Imaging } & \multicolumn{3}{|l|}{ Engine } \\
\hline Author & Ref. & Method & Method Detail & $\begin{array}{l}\text { Frame rate } \\
(\mathrm{f} / \mathrm{s})\end{array}$ & Speed (rpm) & Fuel & $\mathrm{A} / \mathrm{F}$ & $\mathrm{CR}$ \\
\hline Rashidi & [27] & Luminous & High speed consecutive images & 2000 & 1096 & Isooctane & 1.08 & - \\
\hline Berreta & {$[21]$} & Luminous & High speed imaging,hand traced, $\mathrm{NaCl}$ seeding & 5000 & 872,1233 & Isooctane & $1.13-0.98$ & 7.86 \\
\hline Heywood & [28] & Schlieren & Each picture is from different cycle & 1380 & 1380 & $\begin{array}{l}\text { Propane, } \\
\text { hydrogen }\end{array}$ & 1.00 & 7.00 \\
\hline Gatowski & [29] & Schlieren & High speed consecutive images & 2000 & 740,1400 & Propane & 0.9 & 5.75 \\
\hline zur Loye & [25] & 2D visual & Laser scattering, $\mathrm{TiO}_{2}, \mathrm{ZrO}_{2}$ seeding & - & $300-3000$ & Propane & $1.0,0.5$ & 8.00 \\
\hline Keck & [15] & Schlieren & High speed consecutive images, hand traced & 2000 & 1400 & Propane & 0.87 & 5.75 \\
\hline Pischinger & [16] & Schlieren & High speed consecutive images & 25,000 & 1400 & Propane & $\begin{array}{l}1.00,0.77 \\
0.71\end{array}$ & 6.70 \\
\hline Bates & [13] & Luminous & Multi exposure in one frame & 30 (NTSC) & 500 & Propane & $0.6-0.9$ & 9.10 \\
\hline Nakamura & [30] & Luminous & High speed consecutive images & 10,000 & 1500 & Gasoline & 1 & 9.30 \\
\hline Herweg & [31] & Schlieren & Pictures are from different cycle & $\begin{array}{l}\text { Flash light, } \\
\text { pulse } 40 \text { ns }\end{array}$ & $800-2000$ & Propane & 0.77 & 7.30 \\
\hline Bates & [14] & Luminous & Multi exposure in one frame & 30 (NTSC) & 500,1000 & Propane & 0.75 & 9.10 \\
\hline Shen & [32] & Schlieren & High speed consecutive images, hand traced & 20,000 & 500,1100 & Isooctane & $1.00-0.91$ & 7.70 \\
\hline Aleiferis & [18] & Luminous & Double-exposed images & 25 & 1500 & Isooctane & 0.68 & 7.90 \\
\hline Aleiferis & [33] & Luminous & Double-exposed images & 25 & 1500 & Isooctane & $1.00,0.68$ & 7.90 \\
\hline Lee & [34] & $\begin{array}{l}\text { Laser deflection } \\
\text { and Schlieren }\end{array}$ & Comparison between the 2 methods & 3000 & $1200,1500,1800$ & $\begin{array}{l}\text { Liquefied } \\
\text { petroleum gas }\end{array}$ & $\begin{array}{l}0.80,1.10 \\
1.30\end{array}$ & 10.00 \\
\hline Conte & [35] & $\begin{array}{l}\text { Optical and ion } \\
\text { sensors }\end{array}$ & Mapping (no images taken) & - & 2000 & $\begin{array}{l}\text { Gasoline and gas } \\
\text { mixtures }\end{array}$ & 1.00 & 8.70 \\
\hline Gerke & [36] & $\begin{array}{l}\mathrm{OH}- \\
\text { chemiluminesc. }\end{array}$ & High speed imaging & 10,000 & $\begin{array}{l}\text { Compression } \\
\text { machine }\end{array}$ & Hydrogen & $0.36-2.50$ & $\begin{array}{l}(p=5- \\
45 \text { bar })\end{array}$ \\
\hline Bates & [13] & Luminous & Multi exposure in one frame & 30 & 500 & Propane & 0.70 & 9.00 \\
\hline Tahtouh & [37] & Luminous & High speed imaging & 6000 & 1200,2000 & $\begin{array}{l}\text { Isooctane, } \\
\text { methane }\end{array}$ & $1.00,0.80$ & 9.50 \\
\hline Baritaud & [38] & Schlieren & High speed consecutive images, hand traced & 6000 & 500,1040 & Propane & $0.65,0.85$ & 6.00 \\
\hline Tagalian & [39] & Z-Schlieren & 5 cycles analysed & 1400 & 1400 & Propane & 0.90 & - \\
\hline Aleiferis & [40] & Shadowgraphy & High speed, consecutive pictures, 100 cycles & 9000 & 1500 & E85, gasoline & 1.00 & 11.15 \\
\hline Aleiferis & [41] & Chemiluminesc. & High speed, consecutive pictures, 100 cycles & 9000 & 1500 & Alcohols, HCs & 1.00 & 11.15 \\
\hline Herweg & [42] & Luminous & $\begin{array}{l}\text { Experimental work in a side chamber and one- } \\
\text { dimensional model }\end{array}$ & - & $\begin{array}{l}300,500,750 \\
1000,1250\end{array}$ & Propane & $\begin{array}{l}1.00,0.77 \\
0.67\end{array}$ & 7.30 \\
\hline
\end{tabular}

Table 2

Fuel properties.

\begin{tabular}{|c|c|c|c|c|c|c|c|}
\hline \multirow[t]{2}{*}{ Fuel } & \multirow[t]{2}{*}{ Formula (-) } & \multirow[t]{2}{*}{ Molar mass (g) } & \multirow{2}{*}{$\begin{array}{l}\text { Density } \\
\left(\mathrm{kg} / \mathrm{m}^{3}\right)\end{array}$} & \multirow{2}{*}{$\begin{array}{l}\text { Lower heating } \\
\text { value }(\mathrm{MJ} / \mathrm{kg})\end{array}$} & \multirow{2}{*}{$\begin{array}{l}\text { Stoichiometric } \\
\text { A/F ratio }(\mathrm{kg} / \mathrm{kg})\end{array}$} & \multicolumn{2}{|c|}{ Flammability limits in air (V\%) } \\
\hline & & & & & & Lower & Upper \\
\hline Gasoline (approx.) & $\mathrm{C}_{n} \mathrm{H}_{1.87 n}$ & 110 & $720-780$ & 44.2 & 14.60 & 1.0 & 8.0 \\
\hline Isooctane & $\mathrm{C}_{8} \mathrm{H}_{18}$ & 114.23 & 692 & 44.3 & 15.13 & 1.0 & 6.0 \\
\hline Ethanol & $\mathrm{C}_{2} \mathrm{H}_{6} \mathrm{O}$ & 46.07 & 785 & 26.9 & 9.00 & 3.3 & 19.0 \\
\hline Methanol & $\mathrm{CH}_{4} \mathrm{O}$ & 32.04 & 792 & 20.0 & 6.47 & 6.0 & 36.0 \\
\hline E85 & $\mathrm{C}_{\mathrm{n}} \mathrm{H}_{2.88 n} \mathrm{O}$ & 56.29 & 771 & 29.6 & 9.92 & 3.0 & 17.1 \\
\hline M85 & $\mathrm{C}_{\mathrm{n}} \mathrm{H}_{3.74 n} \mathrm{O}$ & 44.37 & 777 & 23.6 & 7.77 & 5.3 & 31.5 \\
\hline
\end{tabular}

two fuels have similar physical properties. Moreover, gasoline is a mixture of hydrocarbons with a composition that is not guaranteed, whereas isooctane is an easily available pure chemical. Previous flame-propagation studies in optical engines did not compare flame propagation characteristics of gasoline and isooctane to verify the two fuels behaved in a similar fashion. Alcohols and blends with gasoline (or isooctane) have been used in piston engines since the engine itself was invented. At present, bio-alcohols are proposed among the candidates for future fuels. Many studies have investigated their emission and performance qualities [49-52,40], but the literature is lacking the relevant optical-engine data. Usually each published study concentrates on one engine geometry (e.g. one compression ratio) and one fuel. There are very few optical data available on comparison of different fuels in the same engine operating conditions. Table 2 lists some of properties of the fuels tested in these engines (from $[26,53]$ ).

\subsubsection{Current contribution}

The main contribution of this paper is statistical characterisation of non-spherical and non-isotropic aspects of flame propagation. A specifically-designed multi-fuel optical engine was used to compare flame-propagation characteristics of isooctane and gasoline. E85 and M85 were also investigated as practical alternative spark-ignition engine fuels and to fill in the gaps in the flame-propagation data base. E85 and M85 were "research grade": they were mixed in house using pure alcohols and isooctane. CR of $8.14: 1$ and 5:1 were chosen to test the fuels: the higher to simulate real engine conditions; and the lower one to provide sufficient contrast from the higher one. Utilising the capability of an extremely sensitive and fast camera, high temporal resolution was achieved, allowing investigation of phenomena like ignition delay and early flame kernel formation. The large number of samples allowed mathematical statistics to be used to find the typical distribution 
of the measured data. It was concluded that elliptical flame structures describe flame propagation more accurately than spherical flame structures in many cases. Therefore a new and more detailed set of combustion data with these fuels has been obtained, and it can be used for validation of CFD and emissions studies.

\section{Experimental apparatus and imaging system}

\subsection{Engine and optical access}

Experiments were carried out in a modified single cylinder fourstroke Briggs \& Stratton engine. Some parameters of the engine are shown in Table 3. Many properties of this research engine are comparable with commercial engines. The engine original lubrication and cooling systems, the valve train, and timing were not modified. The exhaust muffler was taken off and the exhaust port was connected straight into a laboratory extractor. The nozzle of the original carburetor was replaced with a variable area nozzle, so that any air-fuel mixture could be set by varying the fuel and/or air flow. The fuel flow and air flow were measured electronically. The volume change of the fuel stored in a small tank above the carburettor

Table 3

Engine data.

\begin{tabular}{ll}
\hline Description & Value \\
\hline Make & Briggs and Stratton \\
Model NO. & 093432 \\
Type & 4 -Stroke, air cooled, wet sump \\
Valve, head arrangement & 2 -Valve, L-head \\
Bore $\times$ stroke $(\mathrm{mm})$ & $65.1 \times 44.4$ \\
Connection rod ratio & 0.25 \\
Displacement $\left(\mathrm{cm}^{3}\right)$ & 148 \\
Field of view $\left(\mathrm{mm}^{3}\right)$ & $19 \times 50$ \\
Compression ratios & $5.00,8.14$ \\
\hline
\end{tabular}

was measured, and the fuel flow rate was determined with known fuel density. The air consumption was measured using an orifice plate based on the Bernoulli's principle, Fig. 4. The measurement was taken every $0.5 \mathrm{~s}$, and the air/fuel ratio was calculated subsequently. During the whole operation period of the engine, the air/ fuel ratio was monitored to keep a constant air/fuel ratio.

The rig had a $12 \mathrm{~V}$ ignition system containing a BOSCH K12V TCI coil to supply high voltage to the NGK CHSA spark plug. The geometry of the plug had to be modified in order to fit in the cylinder head. The thread, sealing mode and electrical connection had to be changed, however, the electrodes and their gap of $0.7 \mathrm{~mm}$ was not altered. The ignition timing was kept the same, 20 CA degree BTC, for all fuels and operating conditions. Therefore, at the time of ignition the flow field adjacent to the spark was similar for the tested fuels at a given operating point. The position and orientation of the spark plug is illustrated in Fig. 2, and the azimuthal orientation of the spark-plug gap was kept constant in all the experiments. The optical access was gained by a specifically designed cylinder head. The chosen Briggs \& Stratton engine had an air cooled and side valved configuration, which resulted a simpler head design. One of the main design goals was to keep the compression ratio close to ones that real engines have. This restricted the maximum achievable size of field of view. The location and size of optical access was found by ensuring that some portion of the valves and piston were visible and the spark plug placed in the middle. Finally, required grades of materials, minimum wall thickness and cooling surface were determined by Finite Element Analysis. The final version of the research head had similar internal and outer geometrical design to the original one, but the compression ratio became variable using spacers from 5.00 up to its maximum value 8.14. The detailed in-cylinder geometry is illustrated in Fig. 2.

Prior to image recording the engine was heated up using a metal blank instead of the window, which was also pre-heated by a blower torch. The design of the window clamp allowed swapping the blank to the window in a few seconds preserving the temperature of the system. Then, the engine was run an additional $5 \mathrm{~min}$

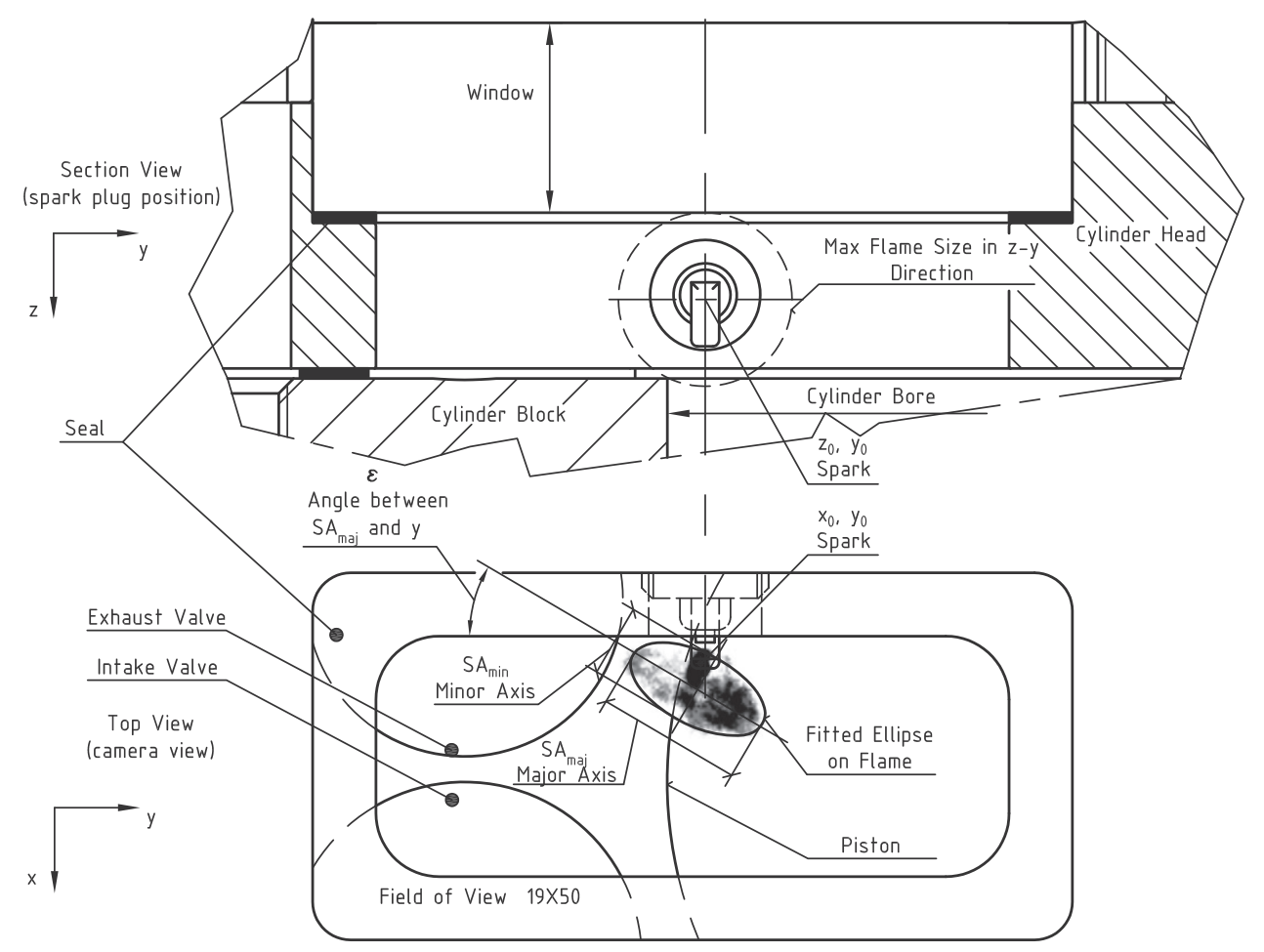

Fig. 2. Section and top views of combustion chamber with fitted ellipse to the flame front. 
Table 4

Details of operating conditions.

\begin{tabular}{llll}
\hline & $\begin{array}{l}\text { Engine speed } \\
(\mathrm{rpm})\end{array}$ & CR & Value \\
\hline Clearance height (mm) at ToI/EoI & 1200 & 5.00 & $32.10 / 30.74$ \\
& & 8.14 & $14.76 / 13.40$ \\
& 1500 & 5.00 & $32.10 / 30.57$ \\
& & 8.14 & $14.76 / 13.23$ \\
Est. residual gas volume fraction (\%) & & 5.00 & 25 \\
& & 8.14 & 14 \\
Volumetric efficiency (\%) & 1200 & & $27.02 \pm(1.35)$ \\
& 1500 & & $27.93 \pm(1.40)$ \\
Pressure at time of ignition (bar) & 1200 & 5.00 & $3.78 \pm(0.19)$ \\
& & 8.14 & $6.29 \pm(0.31)$ \\
& 1500 & 5.00 & $3.97 \pm(0.20)$ \\
Spark duration (ms) & & 8.14 & $7.41 \pm(0.37)$ \\
& & & $1.48 \pm(0.19)$
\end{tabular}

to reach steady operating conditions. For statistical analyses over 100 sets of data were obtained at each engine operating point. The camera memory could only store about 30 sets of data at a time. Therefore each time about 30 sets of data were recorded, and while the engine was running at the same operating point the camera memory was copied to the computer over about $30 \mathrm{~s}$. Then a subsequent set of about 30 data points was obtained, and the process was repeated four times at each operating point. The computer code had a comparison loop that compared the four series of data to each other to check the stability of conditions and to look for contamination on the window. The important factors influencing the initial flame development are summarised in $\mathrm{Ta}$ ble 4 . The volume of the combustion chamber is calculated by the clearance heights as the piston movement is quite small during the initial flame propagation period.

It is difficult to obtain accurate values for residual gas volume so it was estimated by using valve timing and clearance volumes. It can be seen in Fig. 3 that there was only a short period of valve overlap. Moreover, the low volumetric efficiency (at wide open throttle) and positioning of the valve with respect to the head walls suggest that the effect of short-circuiting was not significant. The dynamic effects of the moving working fluids could be neglected.

Thermodynamic conditions were recorded during the tests but were not synchronised with visualisation, so only the mean values are given in Table 4. Each fuel had slightly different pressure curve at compression stroke, but the differences were smaller than the measurement errors.

Table 5 shows a data matrix of the indicated mean effective pressure (IMEP) values and the corresponding coefficient of varience (COV) for each condition and fuel. The ignition timing was kept the same in order to provide a similar flowfield for all fuels. Therefore, Table 5 is only informative of fuel performance.

The computer code could only measure the spark duration when there was no combustion inside the engine (in dark) as it could not distinguish between flame and spark. During the experiments, it was found that the spark length was significantly shorter when there was combustion around it. So the spark length shown in Table 4 was derived from manual analysis of ten randomly chosen combustion images.

It is believed that this optical engine provided a similar representation of real engine processes in production engines to that of other optical engines. The main disadvantage of the designed configuration is the different in-cylinder flow field from the usual pent-roof type 4-stroke automotive engines. On the other hand, the unmodified wet-sump lubrication allowed running the engine at normal operating temperatures without further modifications. At this temperature there was no fuel or oil condensation on the

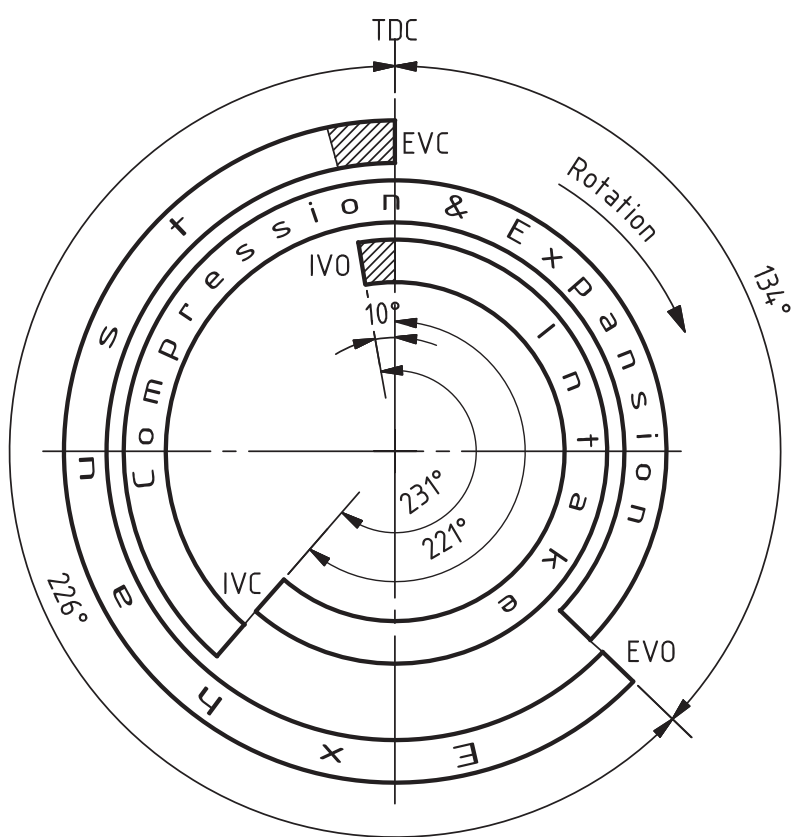

Fig. 3. Valve timing diagram (overlap period hatched).

window to cause fouling. Fouling has been reported as one of the constraints limiting other optical-access engines. Less contamination on windows provided prolonged firing periods and clearer images.

\subsection{Fitting an ellipse to an arbitrarily shaped region}

A fundamental task of automated image analysis and computer vision techniques is to fit geometries to regions or set of points. In two-dimensional space the most primitive approach to model a 2D shape is to fit a circle. The next level to retrieve more information from the model is to fit an ellipse, which (unlike a circle) is not symmetrical about every one of its diameters. In this work ellipses are used to model and analyse the non-isotropic propagation of incylinder flames.

\subsubsection{Fitting methods}

Fitting an ellipse to an arbitrarily shaped region has been studied in considerable detail. There are two basic methods for fitting ellipses: (1) boundary-based and (2) region-based methods. Detailed descriptions of these can be found in [54-56].

Boundary-based methods consider that the arbitrary region consists of a set of points sampled from the region. Prior research in image analysis and computer vision have employed a variety of techniques including linear least squares, weighted least squares, Kalman filtering and robust estimation methods [57,54]. Regionbased methods are frequently used in image processing and were chosen here to determine some geometric characteristics of flames. These methods are detailed by Gonzales and Wintz [55]. They use the moments of a region in calculating the best-fit ellipse $[58,59,56]$, and equalise the second order moment of a region in order to determine the best-fit ellipse. In the case of regular shapes (i.e., region close to an ellipse) the aforementioned methods show no major difference in the result. For in-cylinder flames, regionbased methods are more appropriate as they are less affected by boundary irregularities.

\subsubsection{Determining flame speed from fitted ellipses}

The moment of $(w+q)$ order of a 2 dimensional arbitrary region $(B)$ is given by [60]. 
Table 5

Data matrix of IMEPs and the corresponding COVs for all conditions and fuels.

\begin{tabular}{|c|c|c|c|c|c|c|c|c|}
\hline & \multicolumn{8}{|c|}{ Engine conditions } \\
\hline & \multicolumn{4}{|l|}{$1200 \mathrm{rpm}$} & \multicolumn{4}{|l|}{$1500 \mathrm{rpm}$} \\
\hline & \multicolumn{2}{|l|}{5.00} & \multicolumn{2}{|l|}{8.14} & \multicolumn{2}{|l|}{5.00} & \multicolumn{2}{|l|}{8.14} \\
\hline & IMEP (bar) & $\operatorname{cov}(\%)$ & IMEP (bar) & $\operatorname{cov}(\%)$ & IMEP (bar) & $\operatorname{cov}(\%)$ & IMEP (bar) & $\operatorname{cov}(\%)$ \\
\hline \multicolumn{9}{|l|}{ Fuel } \\
\hline Gasoline & 1.41 & 1.84 & 2.25 & 1.19 & 1.49 & 1.90 & 2.45 & 1.47 \\
\hline Isooctane & 1.33 & 2.38 & 2.10 & 1.31 & 1.52 & 2.27 & 2.31 & 1.75 \\
\hline E85 & 1.23 & 2.45 & 2.07 & 1.33 & 1.32 & 2.08 & 2.27 & 1.77 \\
\hline M85 & 1.40 & 1.80 & 2.32 & 1.16 & 1.59 & 1.80 & 2.48 & 1.59 \\
\hline
\end{tabular}

$M_{w q} \equiv \iint_{B} f(x, y) x^{w} y^{q} \mathrm{~d} x \mathrm{~d} y$

calculated over $B$. For regions where no properties are varied, function $f$ has a value of unity. When $(w+q)$ equals zero, i.e., the zeroth moment is the area of region $B$, the centroids are given by the quotient of the first and zeroth moments:

$\bar{\chi} \equiv \frac{M_{10}}{M_{00}}$

$\bar{y} \equiv \frac{M_{01}}{M_{00}}$

Then, the central moments can be determined evaluating the following integral:

$U_{w q}=\iint_{B} f(x-\bar{x})^{w}(y-\bar{y})^{q} \mathrm{~d} x \mathrm{~d} y$

or can be written in terms of moments:

$U_{00}=M_{00}$

$U_{10}=U_{01}=0$

$U_{20}=M_{20} \frac{M_{10}^{2}}{M_{00}}$

$U_{02}=M_{02} \frac{M_{01}^{2}}{M_{00}}$

$U_{11}=M_{11} \frac{M_{10} M_{01}}{M_{00}}$

Finally, the best-fit ellipse can be determined using the central moments:

$0 \equiv \sqrt{4 U_{11}^{2}+\left(U_{20}-U_{02}\right)^{2}}$

$\epsilon=\frac{1}{2} \tan ^{-1}\left(\frac{2 U_{11}}{U_{20}-U_{02}}\right)$

$S A_{m a j}=\sqrt{\frac{2\left(U_{20}+U_{02}+0\right.}{U_{11}}}$

$S A_{\text {min }}=2 \sqrt{\frac{2\left(U_{20}+U_{02}-0\right.}{U_{11}}}$

where $S A_{m a j}, S A_{\min }$ and $\epsilon$ are the semi-major, minor axes and the orientation angle respectively. In this work bitmap images were acquired from the high-speed camera. These were converted to pixelated images from which the central moment integral were obtained from:

$U_{20}=\frac{1}{n} \sum_{i=1}^{n}\left(x_{i}-\bar{x}\right)^{2}$

$U_{02}=\frac{1}{n} \sum_{i=1}^{n}\left(y_{i}-\bar{y}\right)^{2}$

$U_{11}=\frac{1}{n} \sum_{i=1}^{n}\left(x_{i}-\bar{x}\right)\left(y_{i}-\bar{y}\right)$ and can be fairly easily calculated using a computer code.

\subsubsection{Flame speed derived form optical data}

Once the semi-major and minor axes were calculated for each image, the difference in their length was determined by:

$\Delta d a(t) \equiv d a_{t}-d a_{t-1}$

where in this case da is $S A_{\text {maj }}$ or $S A_{\text {min }}$. Dividing the change in length with the known time interval gives the flame speed at the given time:

$S_{n}(t)=\frac{\Delta d a(t)}{\Delta t}$.

\subsubsection{Shape factor}

There are many ways to arrange geometric parameters of a shape non-dimensionally. Details of shape descriptors can be found in [56]. Usually geometric regions are circular when their descriptor value approaches unity. Here the shape evolution of $S A_{\text {maj }}$ and $S A_{\min }$ are of interest. Their most suitable descriptor is roundness $R N S$, which does not vary with the boundary irregularities (local shape wrinkles or disturbances).

$R N S \equiv \frac{4 A}{\pi D_{F}^{2}}$

where RNS is the large scale shape factor, $A$ is the area of a region and $D_{F}$ is Feret's diameter, the longest distance between any two points along the boundary of a region.

\subsection{Optical path and imaging}

Figure 4 is a schematic representation of the engine test bed. The optical assembly is at the top right corner. Fused quartz was chosen for the optical window as it has the appropriate mechanical, thermal and optical properties. An adjustable first-surface Aluminum mirror passed the emitted light to the Nikon f2.8 Macrolens. The lens had the maximum diameter aperture setting to allow as much light into the camera as possible. With the given focal length, the aperture setting, the subject distance and Circle of Confusion the estimated depth of field (i.e. sharp region) is $\pm 5 \mathrm{~mm}$. The Phantom V2.3 camera was set to record at $15 \mathrm{kHz}$. At this rate the exposure time was $65 \mu$ s and the flame image was recorded in a 256 x 128 pixel array. Spatial and temporal resolution was found to be $0.19 \mathrm{~mm} /$ pixel and $67 \mu$ s respectively. From the camera's internal memory the images were sent to a PC in 24 bit bitmap format. The actual images had only 256 greyscales but the analysing code worked faster with the larger, 24 bit bitmaps rather than the memory saving 8 bit ones. These images were fed into a $C$ language code for analysis, which after some filtering and noise reduction determined the position of useful combustion cycles. The following geometric properties were then calculated for each picture that contained useful data: area; perimeter; mass centre coordinates; 


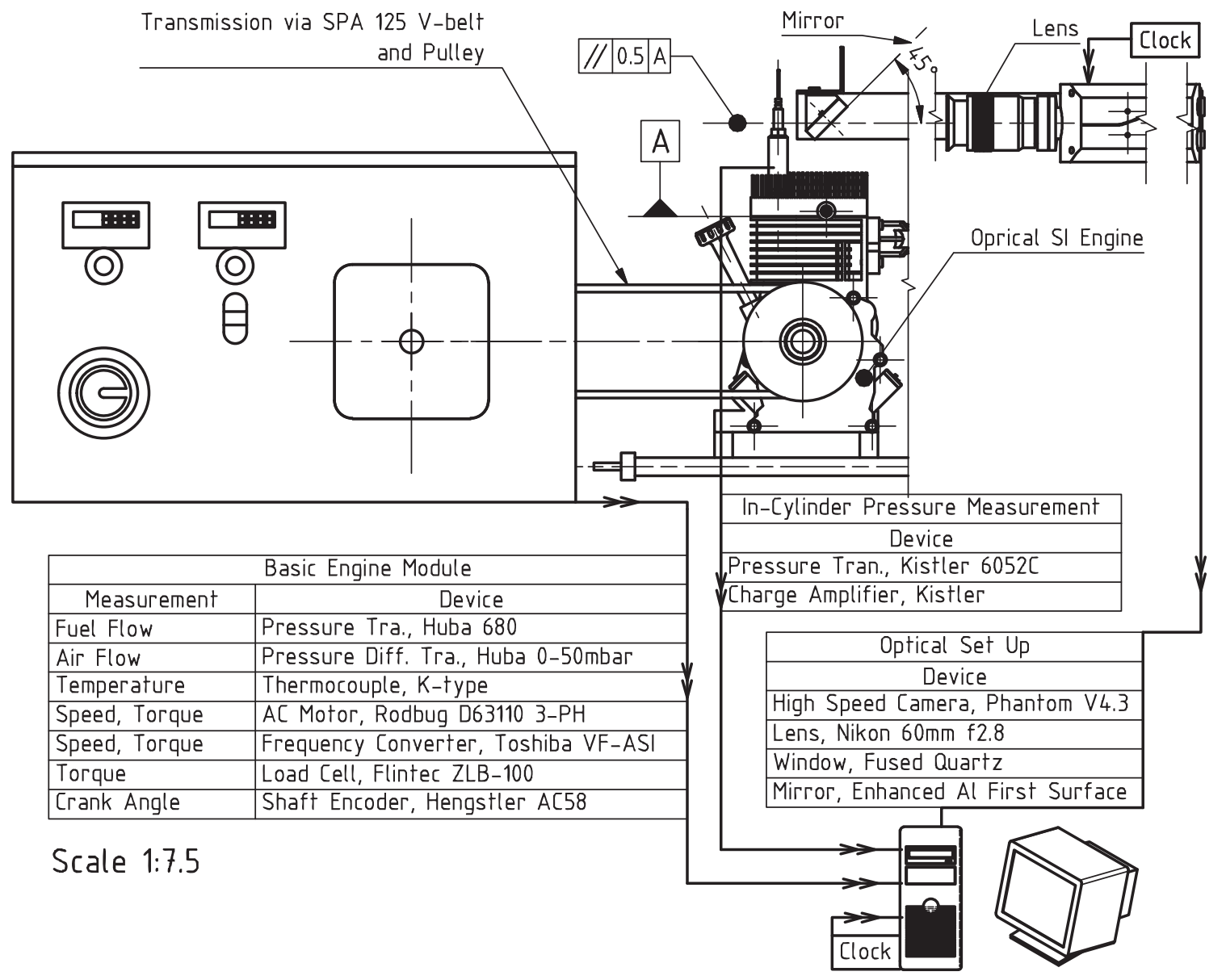

Fig. 4. Schematic of the experimental rig: layout and components.

$x-y$ terminal points coordinates; best fit circle; best fit ellipse; circularity; roundness; solidity; ratio of perimeters; and different shape factors.

\subsection{Uncertainties}

During recording, especially at the early stages of flame initiation, the experimental apparatus had to capture flames with low light intensity for short times. Therefore, the optical set up was calibrated to its highest sensitivity. This meant one of the major sources of uncertainties was light entering the optical path from outside. The underground location of the laboratory helped to provide nearly complete darkness for the tests. High-transparency window material and a high-reflectivity optical mirror were used, therefore errors arising from scattering, absorption, etc. were neglected. Errors from the complementary metal-oxide semiconductor (CMOS) sensor and the computers' internal clock were also neglected. Changes in the air fuel mixture, quality of sparks, distance of engine and CMOS sensor were considered as random uncertainties. These arose from the combination of an infinitely large number of infinitesimally small errors, which was expected to result in a normal frequency distribution, according to the Central Limit Theorem in statistics [61]. Figure 5 is typical of statistical data obtained for all conditions in this research. It illustrates that the data have a normal distribution, and that statistical analysis of the data with normal-distribution statistics is a justified approach.

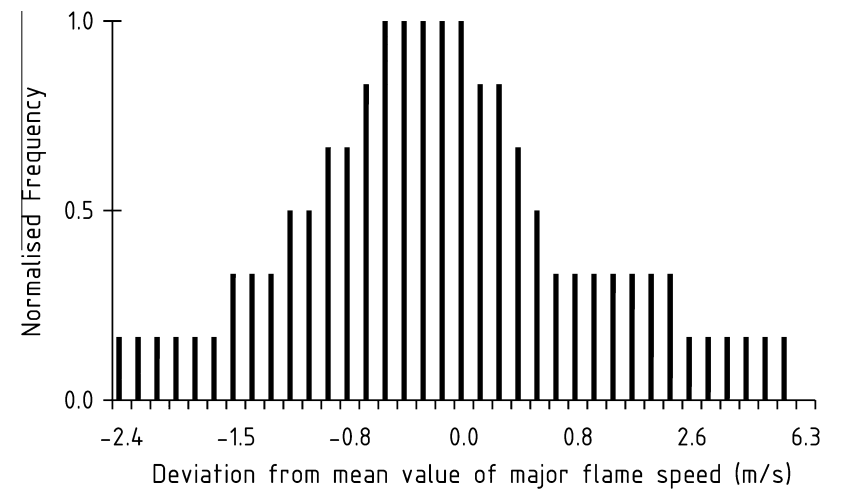

Fig. 5. Sample data distribution, in this case for $M 85,1200 \mathrm{rpm}, C R=5.00$, at $804 \mu \mathrm{s}, S_{t=804}=(5.9 \pm 0.15) \mathrm{m} / \mathrm{s}$.

\section{Results and discussion}

The quantitative and direct comparison of flame speed measurements in optical engines is difficult. The wide selection of fuels, operating conditions and the optical engines themselves produce very different in-cylinder conditions. Many parameters such as ignition modes [31], spark plugs [19], electrode gaps, valve motion and timing [15] and engine geometries differ from engine to engine, not mentioning the operational factors like engine speed or compression ratio, as shown in Table 1. Every factor, such as a relatively small change of the direction of a spark plug electrode, 
Table 6

Derived flame speed values using the EQR method in different optical engines.

\begin{tabular}{|c|c|c|c|c|c|c|c|}
\hline Author & Reference & $\begin{array}{l}\text { Engine speed } \\
(\mathrm{rpm})\end{array}$ & Fuel & $\begin{array}{l}\text { Air/fuel } \\
\text { ratio }\end{array}$ & $\mathrm{CR}$ & $\begin{array}{l}\text { Combustion chamber } \\
\text { geometry }\end{array}$ & $\begin{array}{l}S_{n}(\mathrm{~m} / \mathrm{s}) \text { at } 1000 \mu \mathrm{s} \text { after ToI (equivalent radius } \\
\text { method) }\end{array}$ \\
\hline Ihracska & - & 1500 & Isooctane & 1.00 & 8.14 & Rectangular & 10.4 \\
\hline Ihracska & - & 1500 & Gasoline & 1.00 & 8.14 & Rectangular & 10.3 \\
\hline Ihracska & - & 1500 & E85 & 1.00 & 8.14 & Rectangular & 9.1 \\
\hline Ihracska & - & 1500 & M85 & 1.00 & 8.14 & Rectangular & 14.4 \\
\hline Pischinger & [16] & 1400 & Propane & 1.00 & 6.70 & Square & 4.1 \\
\hline Keck & [15] & 1400 & Propane & 0.87 & 5.75 & Square & 6.1 \\
\hline Herweg & [31] & 1250 & Propane & 1.00 & 7.30 & Cylindrical & 10.1 \\
\hline Aleiferis & [43] & 1500 & Isooctane & 0.60 & 7.90 & Pentroof & 4.9 \\
\hline Aleiferis & [40] & 1500 & Gasoline & 1.00 & 11.15 & Pentroof & 5.0 \\
\hline Aleiferis & [40] & 1500 & E85 & 1.00 & 11.15 & Pentroof & 4.0 \\
\hline
\end{tabular}

could have significant effect on the flame development [18]. Therefore, the best comparison can be made between fuels or operating points if the data is collected from the same engine with the same setup. For the purpose of comparison and cross discussion, the flame speed was re-calculated from the recorded optical data based on the equivalence radius method, as summarised in Table 6 . Moreover, the comparison of flame shape is even more difficult as it is not only related to various engine variables listed above but also to different modes of analysis. There are numerous methods have been proposed in the literature to calculate shape parameters and there is still no consistency so far. For this paper, Roundness was chosen as only the overall shapes was of interest and the local disturbances (wrinkling) could not be captured accurately due to the limitation in the spatial resolution. No roundness data has been found on in-cylinder flame in the literature. Table 6 shows the measured flame speed at a chosen time, $1000 \mu \mathrm{s}$ after ignition. Despite of different engine geometries and operating conditions, the flame speed has the same magnitude for each fuel. It should be noted that there are very few flame speed data available for early stages combustion in SI engines, especially those with satisfactory temporal resolution, a wider quantitative comparison appears impossible. Qualitatively, the flame speed trend obtained among different experiments is consistent. It has an initial high value due to the spark boosted combustion, followed by a minimum value that occurs between 200 and $500 \mu$ s, and then a fairly steady increase until the end of the investigated period. Such a trend shows good agreement with the computational model of Herweg and Maly [42] for flame kernel formation in spark ignition engines. Considering the very different engine geometries, ignition modes and fuel mixing methods, the result is surprisingly well matched. In addition, the flame speed measurement results of gasoline and E85 were compared to Aleiferis' findings [40]. It was found that the ratio of the flame speeds of these two fuels in the current study was similar to the one found in Aleiferis' work. Gasoline showed a faster travelling flame by $(19 \pm 6 \%)$ at $1000 \mu$ s after ignition. Apart from the absolute values, which shall be different among different work, the results are comparable, which suggests that the flame propagation characteristics are similar in SI engines for the earliest stages and is not engine geometry dependent. It is likely that the main controlling factor for early flame speed shall be the initial high energy input from the spark. Consequently, the finding of this study can be extrapolated to other engines.

Isooctane and gasoline flames and some fitted ellipses are shown in Fig. 6 at the condition of 1200, $1500 \mathrm{rpm}$ and CR $=5.00$. The slowest flame propagation was observed at $1200 \mathrm{rpm}$ and $C R=5.00$. The last image is the $41 \mathrm{st}$ in the particular series where the travelling flame reaches the edge of field of view. In Fig. 6 only seven images are shown. The first three are continuous with temporal resolution of $67 \mu \mathrm{s}$. Then the next three were selected randomly, and the final one is the last image in the series.
In $3 \mathrm{D}$ the flame boundary reached the combustion chamber long before it reached the edges of the visible area (Fig. 2). Considering the geometry of the combustion chamber, it was assumed that the flame speed vector in the $\mathrm{z}$ direction had always the same or smaller absolute values than the major flame speed vector at a given time. In the 3D space, the most distorted flames and the fastest ones did reach the combustion chamber walls and the piston at the end of the investigated period $(1500 \mu \mathrm{s})$. However, for the vast majority of cases, there was no contact between the flames and the walls. When the contact did happen, a number of new variables should be added to the flame propagation equations to derive true values of flame speeds. However as there were only relatively small number of data points with contact and its area was small, the effect of it was considered as a small random error. The visual analysis of the gathered images showed a distinct difference in the physical appearance of the flame for the two fuel types, hydrocarbons and alcohols blends. Less luminous flames were found for the latter and higher intensity was seen in images of isooctane and gasoline with local maximums randomly distributed. This is likely to be the result of the simpler and shorter molecule structure of the alcohols. As the longer chains of hydrogen and carbon atoms of isooctane and gasoline required more time for dissociate and complete combustion, there was more unburnt carbon and soot present in flames than in the case of alcohols. The higher soot concentration resulted in greater broad spectrum luminosity.

Figure 7 shows roundness and flame speed along the major and minor axes plotted against time after ignition and CA degrees for gasoline and isooctane. Similarly Fig. 8 for E85 and M85. In each plot the smaller graph shows the flame speed curve from time after ignition. Each curve reaches a maximum and a minimum value, which will be discussed later. The larger graphs show the same parameters after $200 \mu \mathrm{s}$ after ignition, which is a more-stable region of flame development.

Figures 7 and 8 indicate that the visible flame area first expands and reaches maximum flame speeds of the order $50 \mathrm{~m} / \mathrm{s}$ at about $67 \mu \mathrm{s}$, then it contracts as indicated by minimum flame speeds of the order of $-30 \mathrm{~m} / \mathrm{s}$ at about $134 \mu \mathrm{s}$, and then the flame speeds become positive again. This flame contraction soon after the beginning of ignition is caused by rapid endothermic dissociation of fuel molecules and the formation of radicals in the mixture [62-64]. In order to verify that this flame contraction did not occur because of effects of spark energy changes in time, or ionisation of the gas by the spark plug, experiments were carried out of discharging the spark plug in air and analysing the perimeter of the visible luminous plasma with the same analysis as for the flame front with fuels (Fig. 9). In this case the maximum and minimum "flame speeds" of the gas ionised by the spark plug are about $10 \mathrm{~m} / \mathrm{s}$. When the plasma stabilized $200 \mu$ s after spark discharge its value of roundness remained stationary, around 0.75 . This value de- 


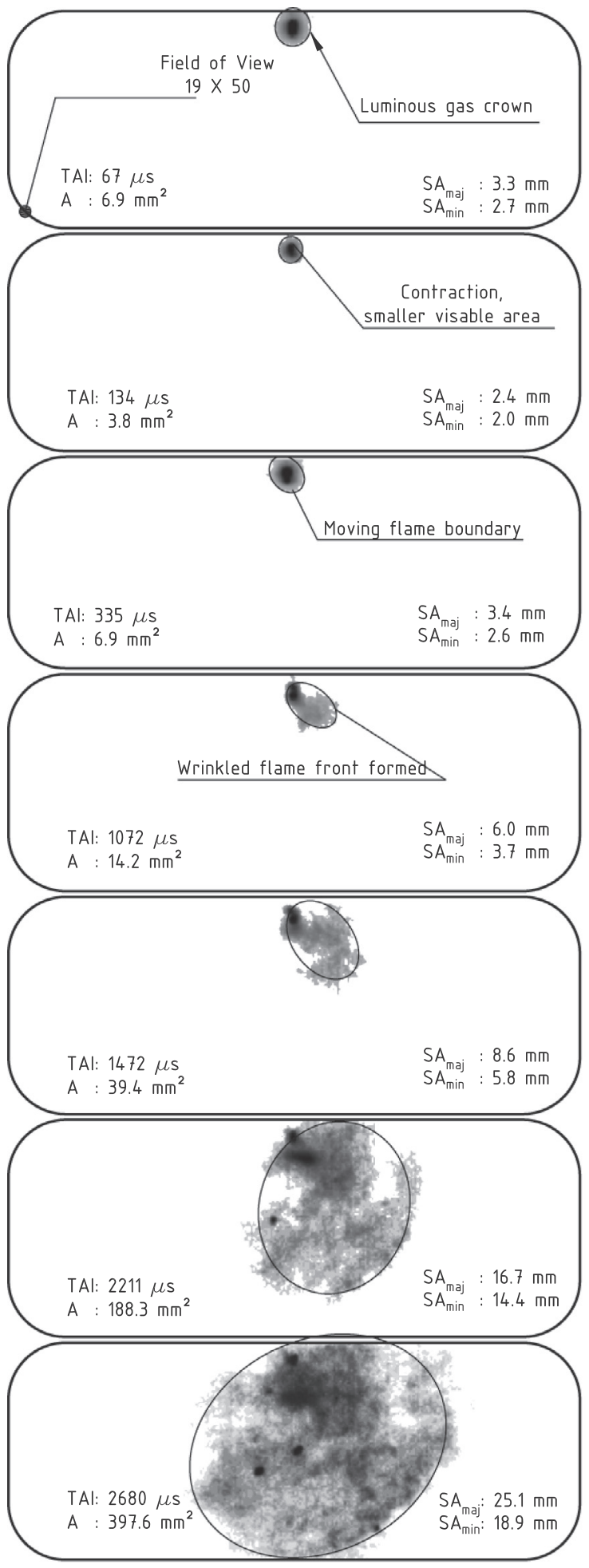

(a)

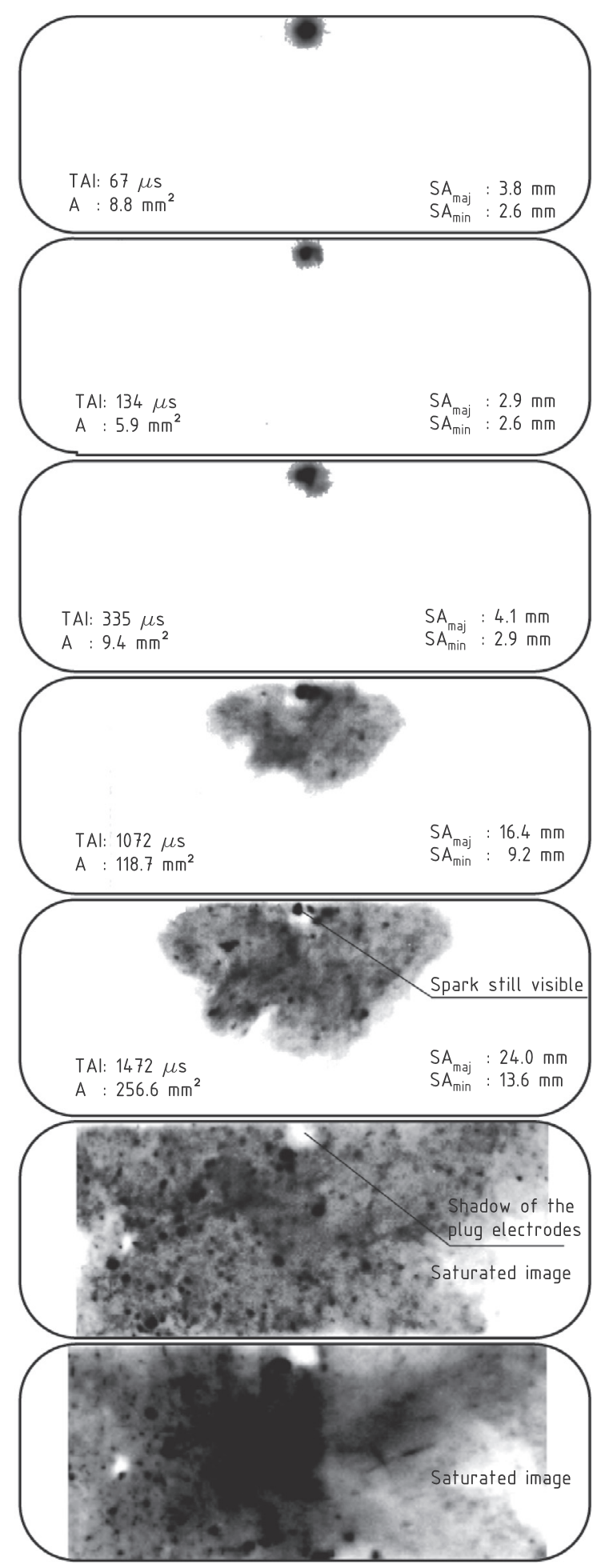

(b)

Fig. 6. Sample flame images a, isooctane, conditions: $1200 \mathrm{rpm}$ and $\mathrm{CR}=5.00 \mathrm{~b}$, gasoline conditions: $1500 \mathrm{rpm}$ and $\mathrm{CR}=5.00$.

scribes the shape of the electric arc between the spark plug electrodes.

The values of the relative standard error (RSE) in major flame speed measurements were plotted in separate graphs for each fuel in Fig. 10. Similar uncertainty values were found for minor flame speed and roundness (these figures are not included for brevity).
In general uncertainty analysis showed that at lower speeds and CR the errors were higher, suggesting a worse air fuel mixing, bigger large scale eddies caused by lower level of turbulence and more spacious combustion chamber respectively, and higher coefficient of variation in these conditions. Variations in the energy of the spark caused higher uncertainty values near $67 \mu$ s after ignition. 

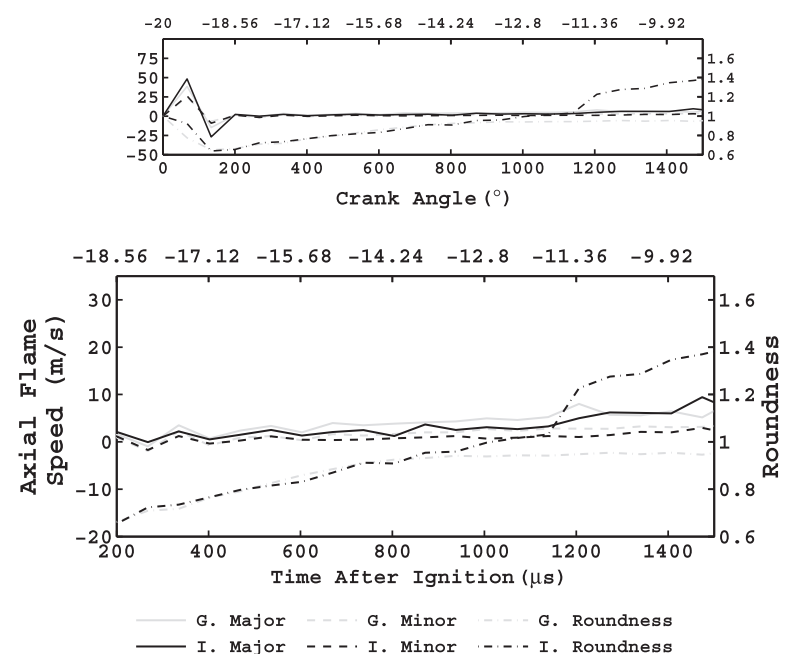

(a)
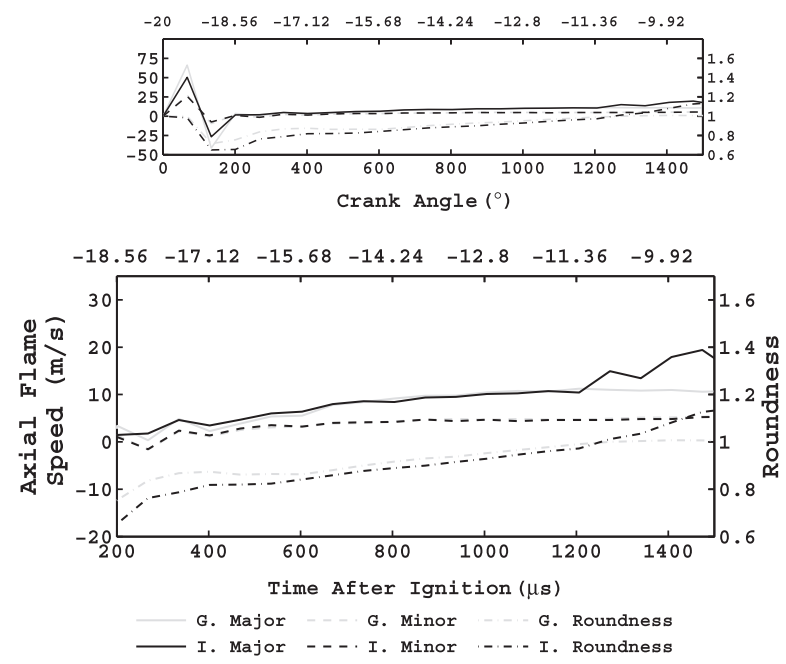

(c)
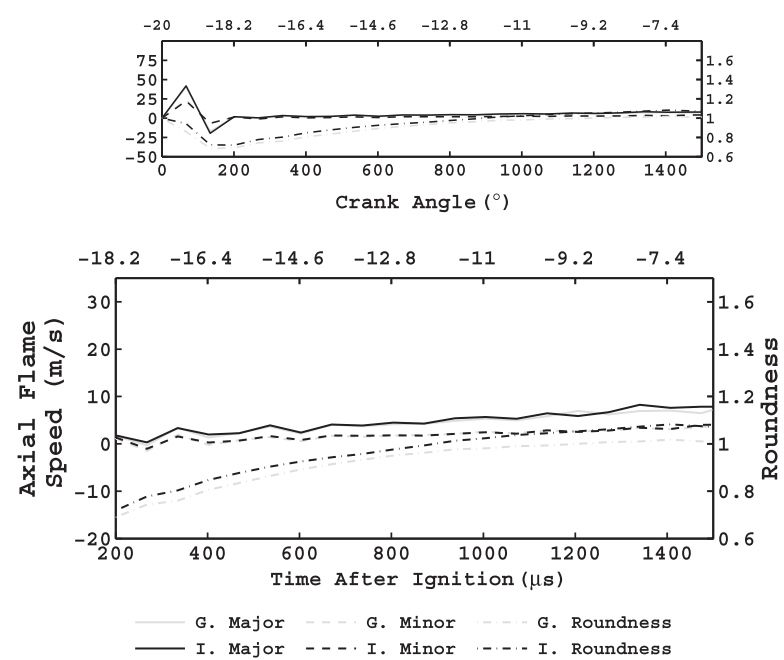

(b)
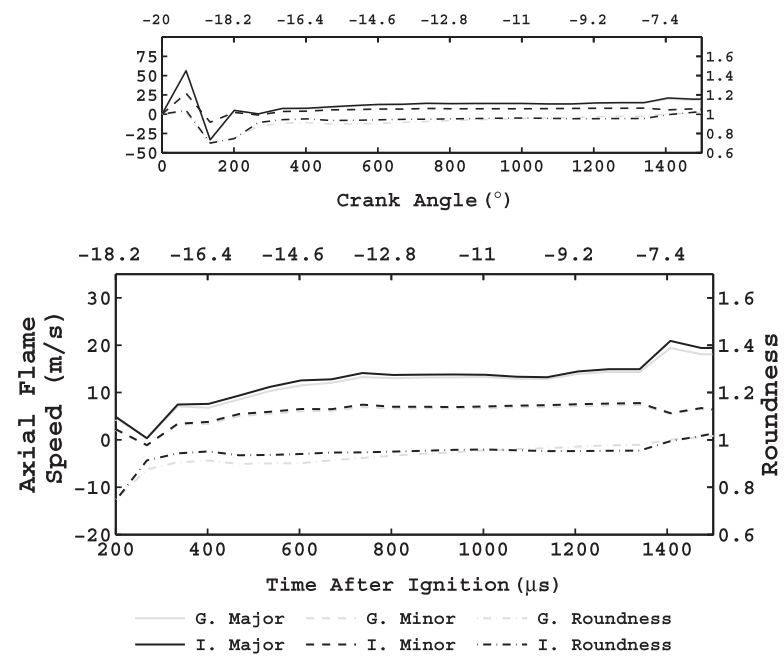

(d)

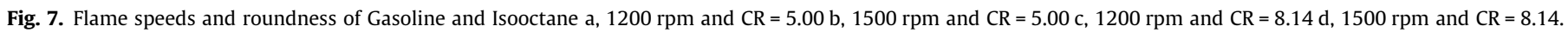

Mixture dissociation into radicals dominated flame propagation at times near $134 \mu$ s after ignition, resulting in lowering uncertainty values from those near $67 \mu \mathrm{s}$ after ignition. The exothermic processes dominate $200 \mu$ s after ignition and later on. The relative magnitude of turbulent fluctuating velocity to flame speed affects uncertainty of measurements. Therefore when the flame speeds are lower (soon after $200 \mu \mathrm{s}$ ) the uncertainties are higher than when flame speeds are higher (e.g. near $1200 \mu \mathrm{s}$ ). Higher speeds and higher compression ratios promote better mixing, so that uncertainties are lower in these cases.

Figures 7 and 8 indicate that the flame front is not spherical. Figure 11 presents a comparison of the spherical and elliptical flame-propagation approaches. In Fig. 11, the major and minor flame speeds and their average were plotted in the same graph with the flame speed calculated using the equivalent radius method. For most of the time investigated, the average speed was similar to the speed calculated from the equivalent radius method but slightly larger, especially when there were larger differences in the major and minor speeds.

The flame shape and its changes in time are important information in the understanding and prediction of in-cylinder processes.
Therefore the ellipse method can provide useful data for CFD and emissions predictions in studies of fuel-engine combinations, and engine design processes [65].

Flame speed and shape factor measurements showed that an ellipses described the contour of combustion better than circles in the first stages of combustion. About the first $800 \mu$ s of propagation were severely affected by the spark causing well elongated flames. This phenomenon was not dependent on fuel or engine operating conditions. At time of ignition, the value of roundness was found to be close to unity in all cases, which was confirmed by images showing a circular glowing area. Then, when the initial high energy got absorbed, the projection of the flame was elongated as the arc and the roundness dropped to about 0.7. Finally, in all investigated cases the calculated value of shape factors started increasing and approaching unity again. There was no description available of the flow field but the phenomenon of the flame becoming more circular later was expected. There is always a larger flux of unburnt charge passing through planes that contain the major axis (or in a general case Feret's diameter) simply because these cross sections have larger areas. This of course is not valid for uniform flows where there is just one plane for the charge 


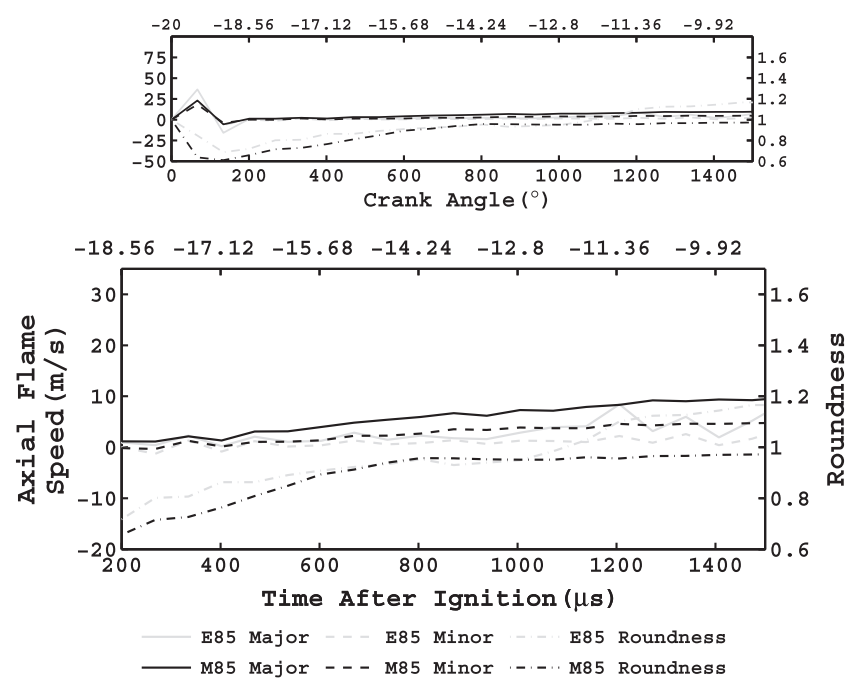

(a)

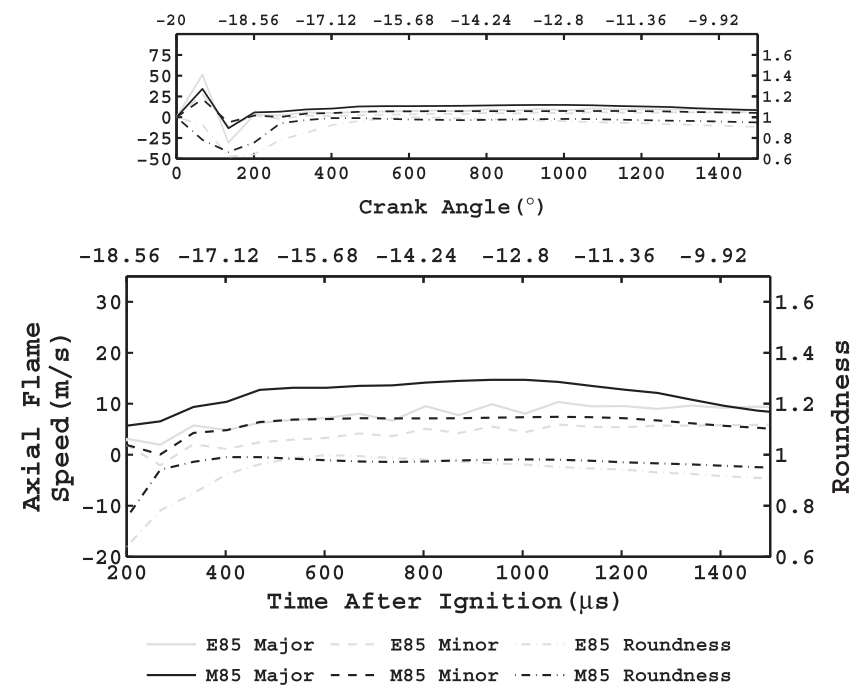

(c)

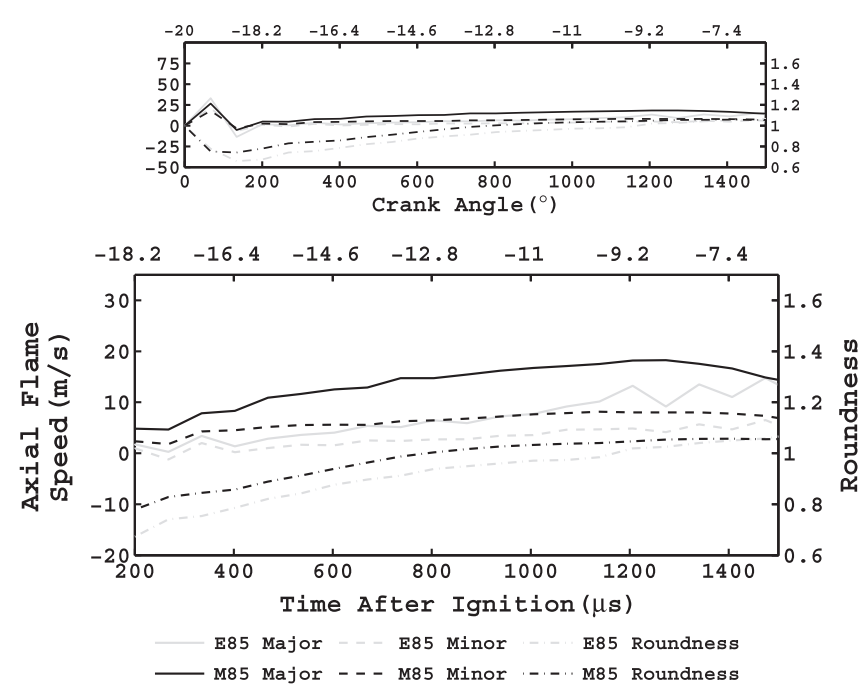

(b)
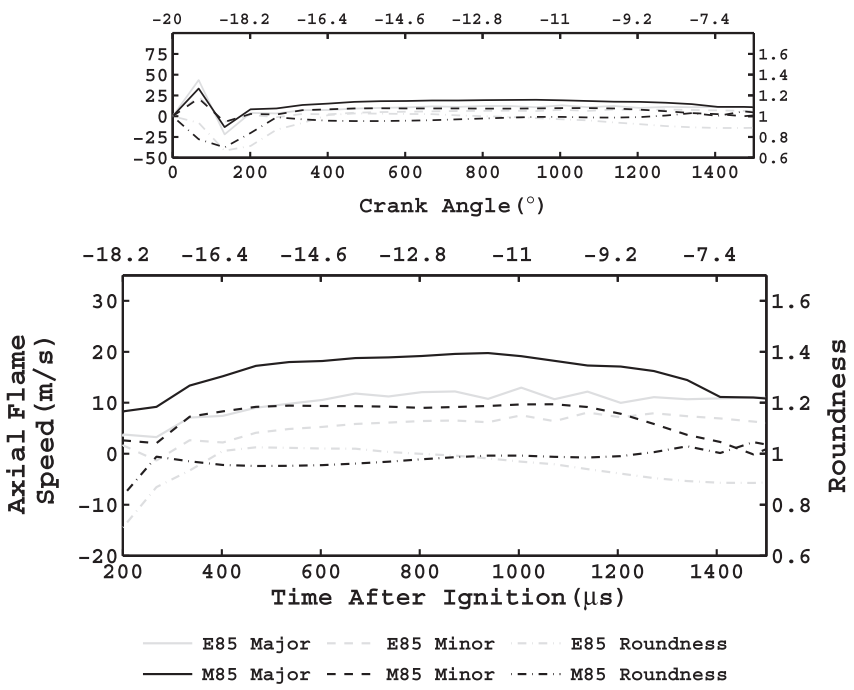

(d)

Fig. 8. Flame speeds and roundness of E85 and M85 a, $1200 \mathrm{rpm}$ and $\mathrm{CR}=5.00 \mathrm{~b}, 1500 \mathrm{rpm}$ and $\mathrm{CR}=5.00 \mathrm{c}, 1200 \mathrm{rpm}$ and $\mathrm{CR}=8.14 \mathrm{~d}, 1500 \mathrm{rpm}$ and $\mathrm{CR}=8.14$.

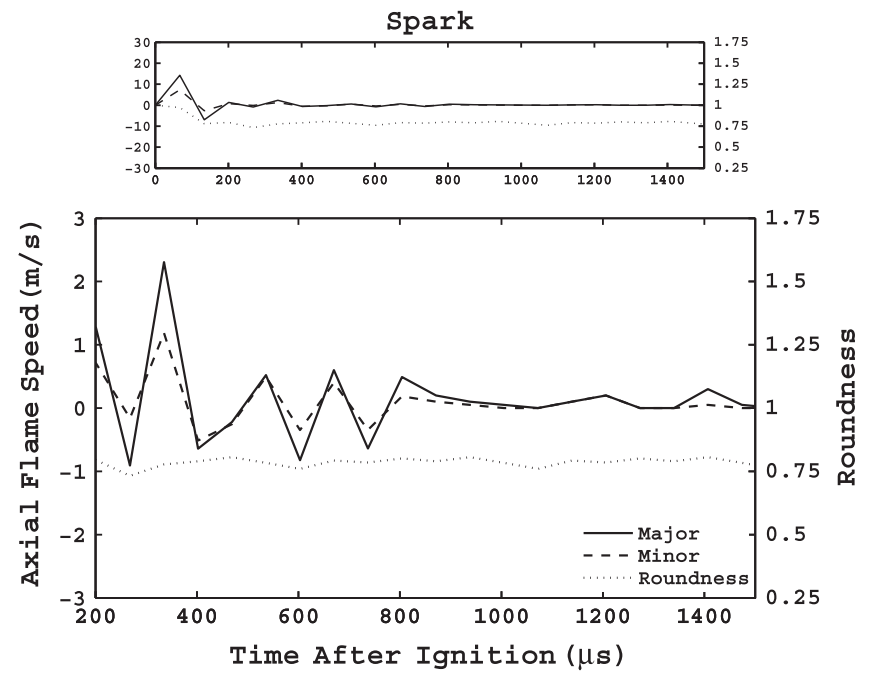

Fig. 9. Flame speed measurement in air (no fuel admitted) at $1500 \mathrm{rpm}$ and $\mathrm{CR}=8.14$. to flow through. In an internal combustion engine there are main directions of flows but as it is turbulent, it could be approximated as a highly random field. The changes in shape were found to be dependent on the engine conditions and fuel. Higher engine speeds and CRs appeared to cause rounder contours; fuels with faster flame speeds also tended to have more regular shapes. Utilising the properties of the ellipse fitting method two flame speed values were calculated normal to each other. It was observed that changes in the magnitude of one flame speed component corresponded to the change in the magnitude of the other one. Therefore, these peaks were caused by a large scale in-cylinder process rather than some local disturbance.

Isooctane (major: 13.76, minor: 7.05) (all flame speed data have a unit of $\mathrm{m} / \mathrm{s}$ and at condition of $\mathrm{CR}$ : 8.14 ; engine speed:: 1500 rpm; TAI: $1000 \mu$ s] and E85 (major: 12.97, minor: 7.55) were found to have more unstable behaviour in combustion; their flame speed curves had more fluctuations than the other two fuels. These two fuels showed the largest changes in shape, sometimes exceeding unity of their shape factors. It seemed that all fuels would sooner or later reach a fairly stable flame speed value depending on the operating conditions. The rate of stabilizing was found to be the 


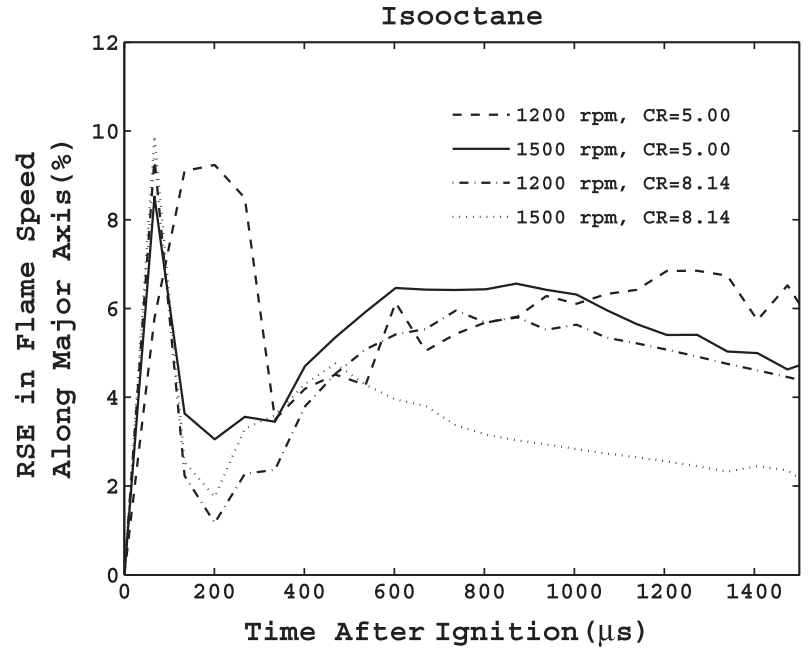

(a)

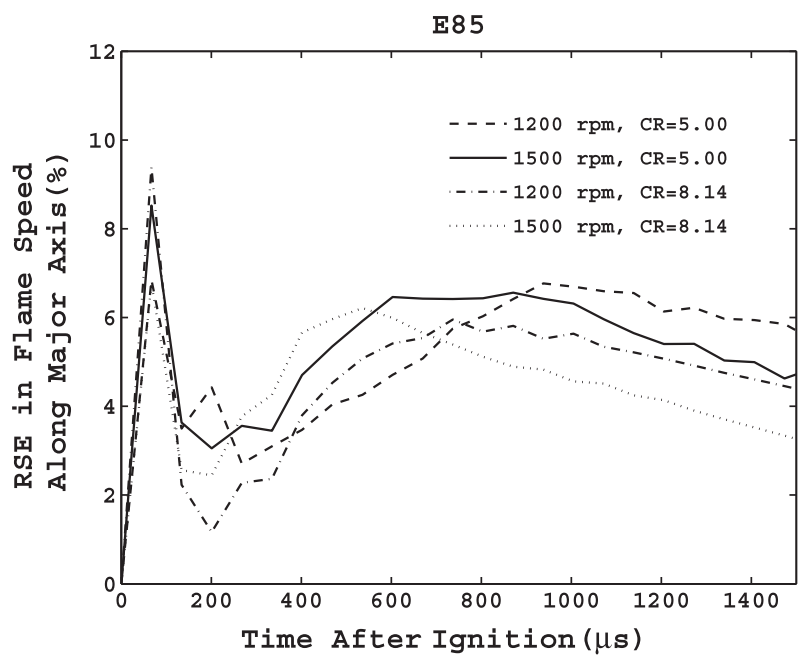

(c)

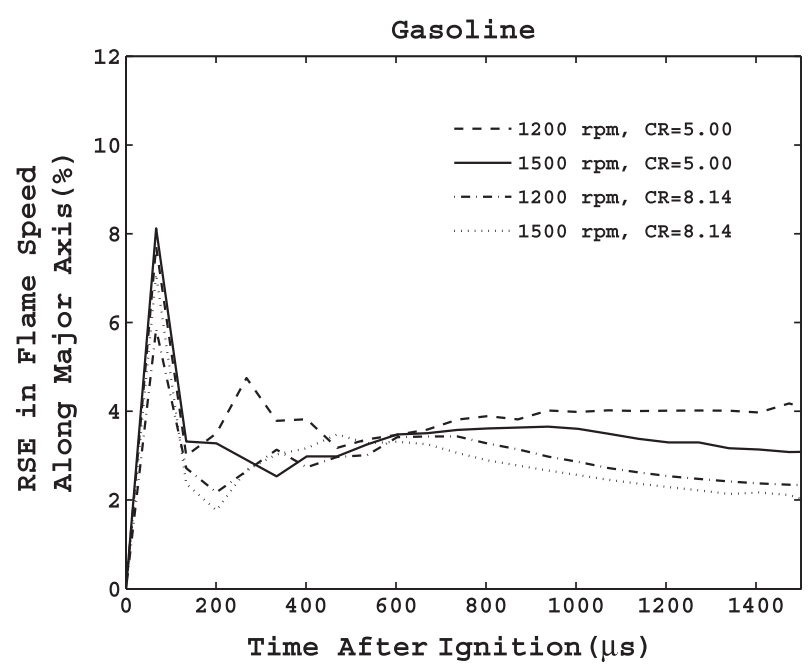

(b)

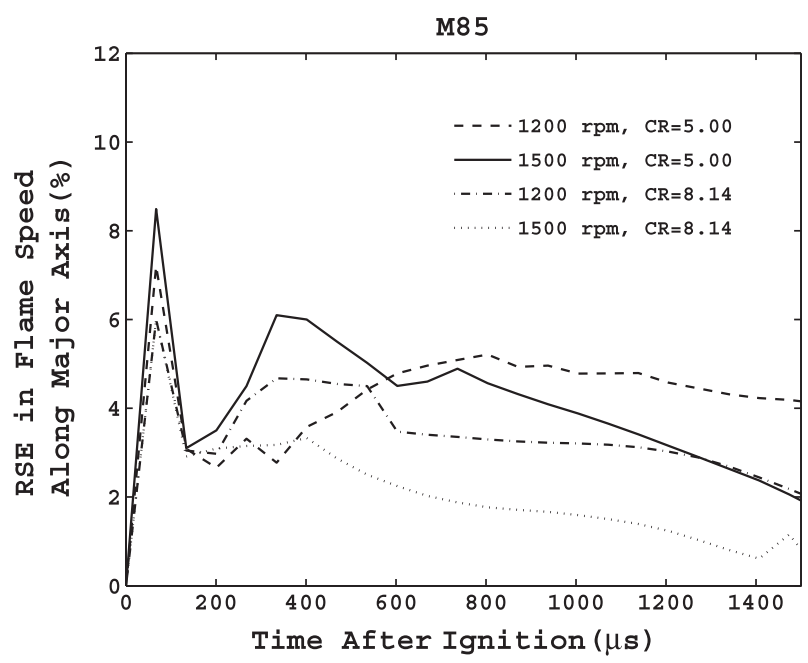

(d)

Fig. 10. Errors in calculated flame speed along the major axis.

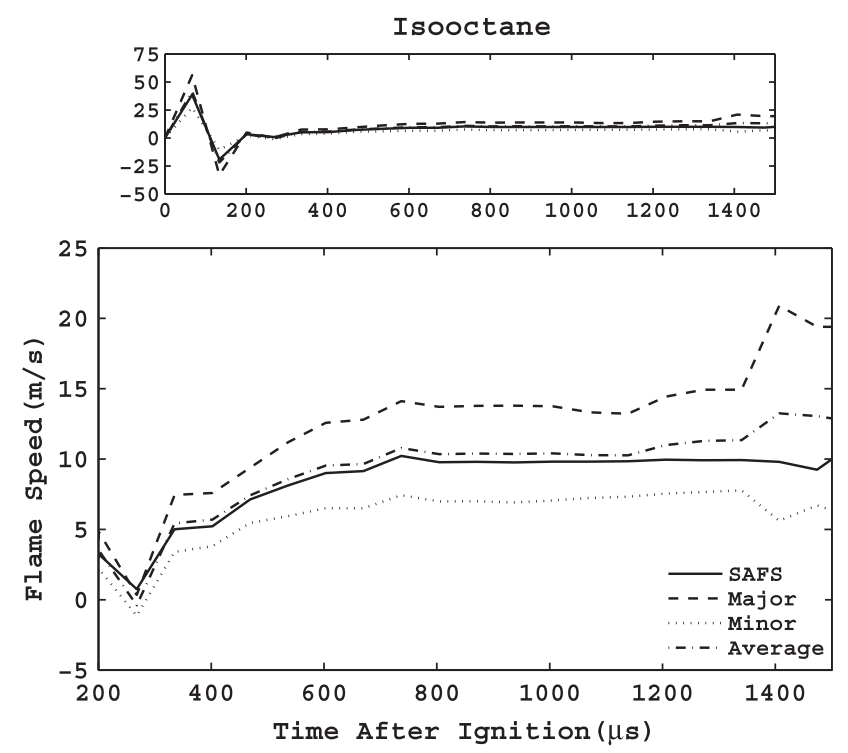

Fig. 11. Comparison between the flame speed of isooctane with the spherical and elliptical methods. The results are similar for the other fuels. lowest for isooctane, which in most cases had increasing flame speeds until the end of recording. In Table 7 flame speed results are shown for all conditions and fuels. Moreover, in order to compare fuels directly with each other the EQR method values were normalised by ones of isooctane. Similar flame speed values were measured for isooctane and gasoline (major: 13.20, minor: 6.70), and most of the time the trend of their change in flame shape showed agreement. As it can be seen from Fig. 7 their flame speed curves were overlapping, apart from the earliest times which were associated with higher uncertainties. Their similarity was more obvious at higher speed and CR where the normalised values showed only a couple of percentage points difference but the largest difference was only about $15 \%$. In the case of gasoline, the results were only informative as its chemical properties were not guaranteed. The highest and most stable flame speeds were found in the case of M85 (major: 19.13, minor: 9.69) which reached its stationary values first. Also, the roundest contours were recorded for this fuel, with fairly low errors in the measurements. This might be a result of the higher flame speed as fluctuating and random incylinder flows had less effect on the flame propagation. A large difference in flame speed was observed form the other fuels especially for the low speed, CR measurements. It was interesting to 
Table 7

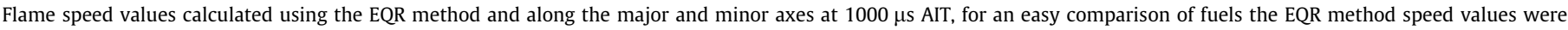
normalised to flames peeds values of isooctane.

\begin{tabular}{|c|c|c|c|c|c|c|c|c|c|c|c|c|c|c|c|c|c|}
\hline \multirow{2}{*}{$\begin{array}{l}\text { CR } \\
(-)\end{array}$} & \multirow{2}{*}{$\begin{array}{l}\text { Engine } \\
\text { speed } \\
(\mathrm{rpm})\end{array}$} & \multicolumn{4}{|c|}{ Isooctane } & \multicolumn{4}{|c|}{ Gasoline } & \multicolumn{4}{|l|}{ E85 } & \multicolumn{4}{|l|}{ M85 } \\
\hline & & $\begin{array}{l}\text { Major } \\
(\mathrm{m} / \mathrm{s})\end{array}$ & $\begin{array}{l}\text { Minor } \\
(\mathrm{m} / \mathrm{s})\end{array}$ & $\begin{array}{l}\text { EGR } \\
\text { method } \\
(\mathrm{m} / \mathrm{s})\end{array}$ & $\begin{array}{l}\text { Ratio to } \\
\text { isooctane } \\
(-)\end{array}$ & $\begin{array}{l}\text { Major } \\
(\mathrm{m} / \mathrm{s})\end{array}$ & $\begin{array}{l}\text { Minor } \\
(\mathrm{m} / \mathrm{s})\end{array}$ & $\begin{array}{l}\text { EGR } \\
\text { method } \\
(\mathrm{m} / \mathrm{s})\end{array}$ & $\begin{array}{l}\text { Ratio to } \\
\text { isooctane } \\
(-)\end{array}$ & $\begin{array}{l}\text { Major } \\
(\mathrm{m} / \mathrm{s})\end{array}$ & $\begin{array}{l}\text { Minor } \\
(\mathrm{m} / \mathrm{s})\end{array}$ & $\begin{array}{l}\text { EGR } \\
\text { method } \\
(\mathrm{m} / \mathrm{s})\end{array}$ & $\begin{array}{l}\text { Ratio to } \\
\text { isooctane } \\
(-)\end{array}$ & $\begin{array}{l}\text { Major } \\
(\mathrm{m} / \mathrm{s})\end{array}$ & $\begin{array}{l}\text { Minor } \\
(\mathrm{m} / \mathrm{s})\end{array}$ & $\begin{array}{l}\text { EGR } \\
\text { method } \\
(\mathrm{m} / \mathrm{s})\end{array}$ & $\begin{array}{l}\text { Ratio to } \\
\text { isooctane } \\
(-)\end{array}$ \\
\hline 5.00 & 1200 & 3.10 & 1.21 & 1.57 & 1.00 & 2.48 & 1.36 & 1.80 & 1.15 & 2.87 & 1.30 & 1.91 & 1.21 & 7.29 & 3.88 & 4.95 & 3.15 \\
\hline 5.00 & 1500 & 5.66 & 2.44 & 3.70 & 1.00 & 5.31 & 2.58 & 4.12 & 1.11 & 7.71 & 3.57 & 5.20 & 1.41 & 14.69 & 7.36 & 11.01 & 2.98 \\
\hline 8.14 & 1200 & 10.11 & 4.70 & 6.90 & 1.00 & 10.45 & 4.70 & 7.05 & 1.02 & 8.03 & 4.42 & 7.14 & 1.04 & 16.74 & 7.63 & 11.84 & 1.72 \\
\hline 8.14 & 1500 & 13.76 & 7.05 & 10.40 & 1.00 & 13.26 & 6.70 & 10.31 & 0.99 & 12.97 & 7.55 & 9.10 & 0.88 & 19.13 & 9.69 & 14.40 & 1.38 \\
\hline
\end{tabular}

Table 8

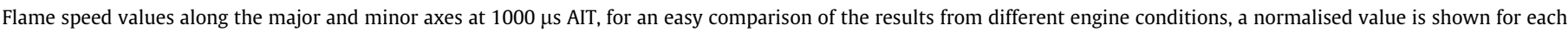
results and conditions.

\begin{tabular}{|c|c|c|c|c|c|c|c|c|c|c|c|c|c|c|c|c|c|}
\hline \multirow{2}{*}{$\begin{array}{l}\text { CR } \\
(-)\end{array}$} & \multirow{2}{*}{$\begin{array}{l}\text { Engine } \\
\text { speed } \\
(\mathrm{rpm})\end{array}$} & \multicolumn{4}{|c|}{ Isooctane } & \multicolumn{4}{|c|}{ Gasoline } & \multicolumn{4}{|l|}{ E85 } & \multicolumn{4}{|l|}{ M85 } \\
\hline & & $\begin{array}{l}\text { Major } \\
(\mathrm{m} / \mathrm{s})\end{array}$ & $\begin{array}{l}\text { Ratio to } \\
\text { CR: } 8.14 \text {, } \\
1500 \mathrm{rpm} \\
(-)\end{array}$ & $\begin{array}{l}\text { Minor } \\
(\mathrm{m} / \mathrm{s})\end{array}$ & $\begin{array}{l}\text { Ratio to } \\
\text { CR: } 8.14 \text {, } \\
1500 \mathrm{rpm} \\
(-)\end{array}$ & $\begin{array}{l}\text { Major } \\
(\mathrm{m} / \mathrm{s})\end{array}$ & $\begin{array}{l}\text { Ratio to } \\
\text { CR: } 8.14 \text {, } \\
1500 \mathrm{rpm} \\
(-)\end{array}$ & $\begin{array}{l}\text { Minor } \\
(\mathrm{m} / \mathrm{s})\end{array}$ & $\begin{array}{l}\text { Ratio to } \\
\text { CR:8.14, } \\
1500 \mathrm{rpm} \\
(-)\end{array}$ & $\begin{array}{l}\text { Major } \\
(\mathrm{m} / \mathrm{s})\end{array}$ & $\begin{array}{l}\text { Ratio to } \\
\text { CR: } 8.14 \text {, } \\
1500 \text { rpm } \\
(-)\end{array}$ & $\begin{array}{l}\text { Minor } \\
(\mathrm{m} / \mathrm{s})\end{array}$ & $\begin{array}{l}\text { Ratio to } \\
\text { CR: } 8.14 \text {, } \\
1500 \mathrm{rpm} \\
(-)\end{array}$ & $\begin{array}{l}\text { Major } \\
(\mathrm{m} / \mathrm{s})\end{array}$ & $\begin{array}{l}\text { Ratio to } \\
\text { CR: } 8.14 \text {, } \\
1500 \mathrm{rpm} \\
(-)\end{array}$ & $\begin{array}{l}\text { Minor } \\
(\mathrm{m} / \mathrm{s})\end{array}$ & $\begin{array}{l}\text { Ratio to } \\
\text { CR:8.14, } \\
1500 \mathrm{rpm} \\
(-)\end{array}$ \\
\hline 5.00 & 1200 & 3.10 & 0.23 & 1.21 & 0.17 & 2.48 & 0.19 & 1.36 & 0.20 & 2.87 & 0.22 & 1.30 & 0.17 & 7.29 & 0.38 & 3.88 & 0.40 \\
\hline 5.00 & 1500 & 5.66 & 0.41 & 2.44 & 0.35 & 5.31 & 0.40 & 2.58 & 0.39 & 7.71 & 0.59 & 3.57 & 0.47 & 14.69 & 0.77 & 7.36 & 0.76 \\
\hline 8.14 & 1200 & 10.11 & 0.73 & 4.70 & 0.67 & 10.45 & 0.79 & 4.70 & 0.70 & 8.03 & 0.62 & 4.42 & 0.59 & 16.74 & 0.87 & 7.63 & 0.79 \\
\hline 8.14 & 1500 & 13.76 & 1.00 & 7.05 & 1.00 & 13.26 & 1.00 & 6.70 & 1.00 & 12.97 & 1.00 & 7.55 & 1.00 & 19.13 & 1.00 & 9.69 & 1.00 \\
\hline
\end{tabular}

see the difference in the behaviour of the two oxygenated fuel blends; while E85 seemed to be showing similar flame propagation characteristics to isooctane, M85 clearly stood apart from E85. As the geometry of the combustion chamber and the operating conditions were the same it is likely that this behaviour of M85 can be explained by the combustion kinetics of methanol. The high laminar flame speed of methanol was explained on the basis of the successive dehydrogenations of the methoxyl radical by Veloo et al. [66] in Ranzi et al. [67]. Finally, Table 8 summarises the effect of different engine speeds and higher CRs on the flame speeds of the tested fuels. In this table the major and minor flame speeds were normalised to the highest value condition (CR: 8.14, engine speed: $1500 \mathrm{rpm}$ ) in order to provide an easy comparison between the engine conditions. A general result is that flame speeds along the major axis are closer to the corresponding maximum values than the ones along the minor axis. This is a direct result of the initially highly distorted shapes becoming more circular as the minor axis elongated more during the flame development. It can be seen that M85 produced somewhat different results from the rest of the fuels. This is probably the result of the aforementioned combustion kinetics. The normalised values for isooctane, gasoline and E85 were quite similar (within about $\pm 10 \%$ ), indicating that the flame propagation characteristics of these fuels tend to react similarly to changes of engine conditions.

\section{Conclusions}

Flame propagation characteristics of isooctane, gasoline, M85 and E85 were recorded using a high-specification camera in a specialty-designed optical-access engine. The high temporal-resolution pictures were analysed with a purpose-built code and statistically compiled. In-cylinder combustion processes with these fuels were investigated in the visible spectra. The high-temporal resolution enabled evaluation of flame kernel formation. A new way of combustion analysis was proposed, where ellipses are used to model the projected flame boundaries. This method elucidated details of the combustion properties and added data to the existing literature on these four fuels. To the authors' knowledge this is the first study on detailed flame speed measurements for M85 from optical engines. Specifically it was concluded that:

1. The spherical flame propagation assumption has certain limitations. Results showed that for some cases the spherical flame front assumption is reasonably valid; but one needs to consider non-isotropic flame propagation in order to model in-cylinder processes more accurately. This is especially so for the earlier combustion stages when the spark causes highly distorted flame contours.

2. For all fuels the flames were more elliptic than circular immediately after ignition, which caused the least round flame-kernel shapes. In all cases, after the first $200 \mu \mathrm{s}$, the elliptic shapes gradually became more circular.

3. Higher flame speeds were observed with increasing engine speed and compression ratio.

4. The standard deviation of the measured values, and uncertainty in values, decreased at higher speeds and compression ratios. Roundness and lower fluctuations of flame speed also indicated more stable flames at those conditions, as a result of higher flame speed, better mixing, and smaller large-scale eddies.

5. For all tested fuels at every operating condition a contraction of the flame was observed on the second recorded image. This is due to the endothermic process associated with the formation of radicals in the mixture.

6. The phenomenon of ignition delay can be defined for SI engines utilising the observed flame-kernel contraction. Ignition-delay is defined as the time between spark ignition and establishment of the steadily expanding flame kernel.

7. A large number of sample observations were plotted. The distribution function showed good agreement with the normal distribution curve. 
8. Isooctane and gasoline showed similar behaviour from the flame propagation point of view, though gasoline produced more shape-invariant flames (uncertainties were lower and flames were more round). The results confirm isooctane (a pure chemical) is a suitable gasoline-blend surrogate as a baseline comparison fuel from a flame propagation point of view. M85 was found to have the fastest flame speed and the most round boundaries. The flame speeds and roundness of the two alcohols were found to be different. In contrast to M85's regularity and fast propagation, E85 showed more shape-variant burning and lower flame speeds.

\section{References}

[1] N. Stern, The Economics of Climate Change, The Stern Review, Cambridge University Press, Cambridge, 2007.

[2] A.M. Namasivayam, T. Korakianitis, R.J. Crookes, K.D.H. Bob-Manuel, J. Olsen, Appl. Energy 87 (3) (2010) 769-778.

[3] T. Korakianitis, A.M. Namasivayam, R.J. Crookes, Int. J. Hydrogen Energy 35 (24) (2010) 13329-13344

[4] T. Korakianitis, A.M. Namasivayam, R.J. Crookes, Prog. Energy Combust. Sci. 37 (1) (2011) 89-112.

[5] T. Korakianitis, A.M. Namasivayam, R.J. Crookes, Fuel 90 (7) (2011) 2384-2395.

[6] C. Rakopoulos, G. Kosmadakis, E. Pariotis, Int. J. Hydrogen Energy 35 (22) (2010) 12545-12560.

[7] D. Veynante, L. Vervisch, Prog. Energy Combust. Sci. 28 (3) (2002) 193-266.

[8] J. Daintith (Ed.), Dictionary of Physics, fifth ed., Oxford University Press Inc., 2005.

[9] C.J. Rallis, A.M. Garforth, Prog. Energy Combust. Sci. 6 (4) (1980) 303-329.

[10] G.T. Kalghatgi, M.D. Swords, Combust. Flame 49 (1-3) (1983) 163-169.

[11] D.R. Lancaster, R.B. Krieger, S.C. Sorenson, W.L. Hull, SAE Int. J. (1976). 760160.

[12] N. Ozdor, M. Dulger, E. Sher, SAE Technical Paper (1994). 940987.

[13] S.C. Bates, SAE Technical Paper (1989). 890154.

[14] S.C. Bates, Combust. Flame 85 (3-4) (1991) 331-352.

[15] J.C. Keck, J.B. Heywood, G. Noske, SAE Technical Paper (1987). 870164.

[16] S. Pischinger, J.B. Heywood, SAE Technical Paper (1988). 880518.

[17] R. Maly, Spark Ignition, Its Physics and Effect on the Internal Combustion Engine, Plenum Press, New York, 1984, pp. 91-129.

[18] P.G. Aleiferis, A.M.K.P. Taylor, J.H. Whitelaw, Y. Ishii, K. Urata, SAE Technical Paper (2000). 2000-01-1207.

[19] J.C. Keck, Symp. (Int.) Combust. 19 (1) (1982) 1451-1466.

[20] F. Matekunas, SAE Int. J. (1983). 830337.

[21] G.P. Beretta, M. Rashidi, J.C. Keck, Combust. Flame 52 (3) (1983) 217-245.

[22] L. Gillespie, M. Lawes, C.G.W. Sheppard, R. Woolley, SAE Technical Paper (2000). 2000-01-0192.

[23] D. Bradley, R. Hicks, M. Lawes, C. Sheppard, R. Woolley, Combust. Flame 115 (12) (1998) 126-144

[24] J.F. Driscoll, Prog. Energy Combust. Sci. 34 (1) (2008) 91-134.

[25] A.O. zur Loye, F.V. Bracco, SAE Technical Paper (1987). 870454.

[26] J.B. Heywood, Internal Combustion Engine Fundamentals, McGraw-Hill, New York, 1988.

[27] M. Rashidi, Combust. Flame 42 (2) (1981) 111-122.

[28] J.B. Heywood, F.R. Vilchis, Combust. Sci. Technol. 38 (5-6) (1984) 313-324.

[29] J.A. Gatowski, J.B. Heywood, C. Deleplace, Combust. Flame 56 (1) (1984) 71-81.
[30] A. Nakamura, K. Ishii, T. Sasaki, SAE Technical Paper (1989). 890322.

[31] G.Z.R. Herweg, Proceedings of the Second International Symposium COMODIA 90 (1990) 173.

[32] H. Shen, D. Jiang, SAE Technical Paper (1992). 922239.

[33] P.G. Aleiferis, A. Taylor, K. Ishii, Y. Urata, Combust. Flame 136 (3) (2004) 283302.

[34] K. Lee, J. Ryu, Fuel 84 (9) (2005) 1116-1127.

[35] E. Conte, K. Boulouchos, Combust. Flame 146 (1-2) (2006) 329-347.

[36] U. Gerke, K. Steurs, P. Rebecchi, K. Boulouchos, Int. J. Hydrogen Energy 35 (6) (2010) 2566-2577.

[37] T. Tahtouh, F. Halter, C. MounaÏm-Rousselle, E. Samson, SAE Int. J. Engines (2010). 2010-01-1451

[38] T.A. Baritaud, SAE Technical Paper (1987). 872152.

[39] J. Tagalian, J.B. Heywood, Combust. Flame 64 (2) (1986) 243-246.

[40] P.G. Aleiferis, J. Serras-Pereira, Z. van Romunde, J. Caine, M. Wirth, Combust. Flame 157 (4) (2010) 735-756.

[41] P. Aleiferis, J. Serras-Pereira, D. Richardson, Fuel, 2013. http://dx.doi.org/ 10.1016/j.fuel.2012.12.088.

[42] R. Herweg, R. Maly, SAE Technical Paper (1992). 922243.

[43] P. Aleiferis, Y. Hardalupas, A. Taylor, K. Ishii, Y. Urata, Combust. Flame 136 (12) (2004) 72-90.

[44] C. Crua, D. Kennaird, M. Heikal, Combust. Flame 135 (4) (2003) 475-488.

[45] C. Yang, H. Zhao, Int. J. Engine Res. 11 (6) (2010) 515-531.

[46] C. Yang, H. Zhao, Combust. Sci. Technol. 183 (5) (2011) 467-486.

[47] H. Zhao, N. Ladommatos, Engine Combust. Instrum. Diagnost. SAE Int. 2001.

[48] S.C. Bates, SAE Technical Paper (1989). 892086.

[49] G.A. Olah, A. Goeppert, G.K.S. Prakash, Beyond Oil and Gas: The Methanol Economy, Wiley VCH, Weinheim, 2009.

[50] R.K. Niven, Renew. Sustain. Energy Rev. 9 (6) (2005) 535-555.

[51] A.K. Agarwal, Prog. Energy Combust. Sci. 33 (3) (2007) 233-271.

[52] A. e. a. J.S. Malcolm, P.G. Aleiferis, Internal Combustion Engines: Performance, Fuel Economy and Emissions: A Study of Alcohol Blended Fuels in a New Optical Spark-Ignition Engine, Institution of Mechanical Engineers, London, 2007.

[53] S. Turns, An Introduction to Combustion: Concepts and Applications, McGrawHill Series in Mechanical Engineering, McGraw-Hill Education, 2000.

[54] K.F. Mulchrone, K.R. Choudhury, J. Struct. Geol. 26 (1) (2004) 143-153.

[55] R. Gonzalez, P. Wintz, Digital Image Processing, Addison-Wesley, Reading, MA, 1987.

[56] J. Russ, The Image Processing Handbook, CRC Press, Florida, 1999.

[57] Q. Ji, M.S. Costa, R.M. Haralick, L.G. Shapiro, ISPRS J. Photogramm. Remote Sensing 55 (2) (2000) 75-93.

[58] A. Jain, Fundamentals of Digital Image Processing, Random House, New York, 1989.

[59] B. Jähne, Digital Image Processing: Concepts, Algorithms, and Scientific Applications, Springer-Verlag, Berlin, 1997.

[60] T. Anderson, Multivariate Statistical Analysis, second ed., John Wiley, 1984.

[61] N.C. Barford, Experimental Measurements: Precision, Error and Truth, John Wiley and Son, 1994.

[62] T. Korakianitis, R.S. Dyer, N. Subramanian, J. Eng. Gas Turbines Power Trans ASME 126 (2) (2004) 300-305.

[63] R.S. Dyer, T. Korakianitis, Combust. Sci. Technol. 179 (7) (2007) 1327-1347.

[64] S. Sazhin, G. Feng, M. Heikal, I. Goldfarb, V. Goldshtein, G. Kuzmenko, Combust Flame 124 (4) (2001) 684-701.

[65] T. Løvås, Combust. Flame 156 (7) (2009) 1348-1358.

[66] P.S. Veloo, Y.L. Wang, F.N. Egolfopoulos, C.K. Westbrook, Combust. Flame 157 (10) (2010) 1989-2004.

[67] E. Ranzi, A. Frassoldati, R. Grana, A. Cuoci, T. Faravelli, A. Kelley, C. Law, Prog. Energy Combust. Sci. 38 (4) (2012) 468-501. 